Rev. Mus. Argentino Cienc. Nat., n.s.

14(1): 57-81, 2012

ISSN 1514-5158 (impresa)

ISSN 1853-0400 (en línea)

\title{
New Patagonian Cretaceous theropod sheds light about the early radiation of Coelurosauria
}

\author{
Fernando E. NOVAS ${ }^{1,2}$, Martín D. EZCURRA ${ }^{1,3}$, Federico L. AGNOLIN ${ }^{1,4}$, \\ Diego POL ${ }^{2,5} \&$ Raúl ORTÍZ ${ }^{6}$
}

${ }^{1}$ Laboratorio de Anatomía Comparada y Evolución de los Vertebrados, Museo Argentino de Ciencias Naturales "B. Rivadavia”, Ángel Gallardo 470 C1405DJR, Buenos Aires, Argentina, fernovas@yahoo.com.ar. ${ }^{2}$ CONICET. ${ }^{3}$ GeoBio-Center, Ludwig-Maximilians-Universität München, Richard-Wagner-Str. 10, D-80333 Munich, Germany. ${ }^{4}$ Fundación de Historia Natural "Félix de Azara", Universidad Maimónides, Hidalgo 775 C1405DJR, Buenos Aires, Argentina. ${ }^{5}$ Museo Paleontológico "Egidio Feruglio", Av. Fontana 140 9100, Trelew, Argentina. ${ }^{6}$ Museo de Paleontología y Geología del Instituto de Formación Docente Continua de General Roca, Mitre 929, 8332 General Roca, Argentina.

\begin{abstract}
Here we describe a new theropod, Bicentenaria argentina nov. gen. et nov. sp., from the early Late Cretaceous of Patagonia. It is represented by more than a hundred bones belonging to different sized individuals, which were buried together in disarticulation after little transportation. The available association of skeletal elements suggests a gregarious behaviour for Bicentenaria, an ethological trait also recorded among other theropod clades. Increasing documentation of monospecific assemblages of different groups of theropods suggests that a gregarious behaviour may have constituted the ancestral condition for Theropoda, at least. Bicentenaria characterizes for the surangular bone with a high dorsal margin and a prominent lateral shelf, a retroarticular process that is low, wide and spoon-shaped, and quadrate bone with its lateral condyle larger than the medial one. Phylogenetic analysis found the Chinese Tugulusaurus and the Patagonian Bicentenaria as successive sister taxa of all other coelurosaurs, thus revealing the importance of the new taxon in the understanding of the early diversification of Coelurosauria. In particular, Bicentenaria amplifies the array of basal coelurosaurs that inhabited Gondwana during the Cretaceous, also including compsognathids, Aniksosaurus and Santanaraptor. Although still restricted to a handful of forms, available information indicates that Gondwana was a cradle for the evolution of different lineages of basal coelurosaurs, different from those documented in Upper Cretaceous beds in the northern landmasses. Analysis of body size distribution in averostran theropods results in the identification of two main episodes of drastic size reduction in the evolutionary history of Coelurosauria: one occurred at the initial radiation of the group (as represented by Bicentenaria, Zuolong, Tugulusaurus, compsognathids, and Aniksosaurus), and a second episode occurred at the early diverification of Paraves or avialans. Reduction in body size may have allowed adult coelurosaurians to exploit ecological niches not occupied before by larger basal averostrans.
\end{abstract}

Key words: Coelurosauria, gregarism, body size reduction, Cretaceous, South America.

Resumen: Nuevo terópodo del Cretácico de Patagonia brinda nuevas evidencias acerca de la radiación temprana de Coelurosauria. En la presente contribución se describe el nuevo terópodo Bicentenaria argentina nov. gen. et nov. sp., del Cretácico Tardío temprano de Patagonia. El nuevo taxón se encuentra representado por más de una centena de huesos pertenecientes a individuos de diferentes tamaños, los cuales fueron enterrados todos juntos en desarticulación, luego de un leve transporte. La asociación disponible de materiales sugiere hábitos gregarios para Bicentenaria, un rasgo etológico también registrado en otros clados de terópodos. La documentación recurrente de asociaciones monoespecíficas de diferentes grupos de terópodos sugiere que los hábitos gregarios pudieron haber constituido la condición ancestral para Theropoda. Bicentenaria se caracteriza por un hueso surangular con un margen dorsal prominente y con una repisa lateral bien desarrollada, un proceso retroarticular que es bajo, transversalmente amplio y en forma de cuchara, y un hueso cuadrado cuyo cóndilo lateral es de tamaño mucho mayor que el medial. El análisis filogenético recuperó al género chino Tugulusaurus y al patagónico Bicentenaria como grupos hermanos sucesivos de los restantes celurosaurios, revelando de este modo la importancia del nuevo taxón para el entendimiento de la radiación temprana de los Coelurosauria. En particular, Bicentenaria amplifica el elenco de celurosaurios basales que habitaron Gondwana durante el Cretácico, incluyendo entre otros a los compsognátidos, Aniksosaurus y Santanaraptor. A pesar de encontrarse restringida a un puñado de formas, la información disponible sugiere que Gondwana fue un importante centro para la evolución de diferentes linajes de celurosaurios basales, diferentes de aquellos representados en el Hemisferio Norte. Un 
análisis de la distribución del tamaño corporal en los terópodos averostros permite identificar dos episodios principales de drástica reducción del tamaño en el curso de la historia evolutiva de los Coelurosauria. El primero de estos episodios ocurrió durante la radiación inicial del grupo (tal como es representado por Bicentenaria, Zuolong, Tugulusaurus, compsognátidos, y Aniksosaurus), y el segundo episodio tomó lugar en la temprana diversificación de Paraves o Avialae. La reducción en la talla corporal pudo haber permitido a los celurosaurios adultos explotar nichos no ocupados anteriormente por terópodos averostros basales de mayor tamaño.

Palabras clave: Coelurosauria, gregarismo, reducción de talla corporal, Cretácico, Sudamérica.

\section{INTRODUCTION}

Coelurosauria includes extant birds and all theropods sharing a more recent common ancestor with Passer domesticus than with Allosaurus fragilis (Holtz et al., 2004). Coelurosaurs were highly diversified during Jurassic and Cretaceous times, including compsognathids, tyrannosauroids, ornithomimosaurians, oviraptorosaurians, therizinosauroids, alvarezsaurids, and dromaeosaurids, among the most notable groups. Most of these clades are well documented in the Northern Hemisphere, and although the record of Coelurosauria in the southern landmasses is still limited, discoveries produced in Patagonia in the last 15 years have favourably changed this situation (Novas, 2009). In particular, the fossil record of non-maniraptoran coelurosaurs in Gondwana is currently composed by Mirischia asymmetrica (Santana Formation, Aptian, Brazil; Naish et al., 2004) and Nqwebasaurus thwazi (Kirkwood Formation, probably Valanginian; De Clerk et al., 2000), both possible compsognathids, and the yet poorly understood Aniksosaurus darwini (Lower Bajo Barreal Formation, Cenomanian; Martínez \& Novas, 2007) and Santanaraptor placidus (Santana Formation, Aptian, Brazil; Kellner, 1999).

Here we enlarge the list of Gondwanan coelurosaurs with the description of the new small-sized species Bicentenaria argentina nov. gen. et nov. sp. Bicentenaria is represented by several cranial and postcranial bones of multiple individuals that increase the taxonomic and morphological diversity of basal coelurosaurs in Gondwana. A comprehensive phylogenetic analysis of Coelurosauria recovers an unexpected high diversity of plesiomorphic lineages in the southern continents, and a twostep evolutionary trend towards the reduction of body size and mass among Coelurosauria, in the line leading to birds.

Institutional abbreviations. AMNH, American Museum of Natural History, New York; MPCA, Museo Provincial "Carlos Ameghino", Cipoletti, Río Negro; USNM, United States National Museum, Washington D.C.

\section{MATERIALS AND METHODS}

\section{Collected material of Bicentenaria argentina}

The skeletal remains of Bicentenaria argentina were collected by Mr. Raul Spedale in 1998 during an exceptional fall in the water level of the Ezequiel Ramos Mexía Reservoir (Fig. 1). All the bones were collected from a single quarry roughly 40 centimeters long, 30 centimeters wide, and 50 centimeters thick (R. Spedale, pers. comm.). The recovered bones are well preserved and lack signs of aerial exposure or scavenging before burial. Unfortunately, the bones suffered several breakages during the excavation process and no taphonomic information was collected during the process. Nevertheless, the bones were buried almost probably in disarticulation, as revealed by a block of sandstone still embedding a partial sacrum and fragments of the corresponding right iliac blade, that are chaotically attached with a fragment of left maxilla, four caudal vertebrae of different sections of the tail, as well as with the proximal end of a cranial dorsal rib. This kind of preservation indicates that bones of different individuals were transported and mixed up before their final burial. The collected bones include three femora of the left side with roughly the same size (approximately $31 \mathrm{~cm}$ in length), thus indicating that the fossil assemblage is made up by, at least, three large different specimens. These large femora match with the size observed in several isolated dorsal, sacral and caudal vertebrae with a closed neurocentral suture. Thus, these large individuals would not be juveniles at the time of their death (Brochu, 1996; Irmis, 2007). Besides, the existence of a right distal femur with an identical morphology, but considerably smaller than the largest ones, indicates the presence of probably younger individuals in the bone assemblage. This statement is supported by the presence of a fragmentary maxilla bearing a tiny tooth with a crown height of $8 \mathrm{~mm}$, obviously corresponding to a juvenile individual. In summary, the bone assemblage seems to be made up by different sized juvenile and adult specimens. 


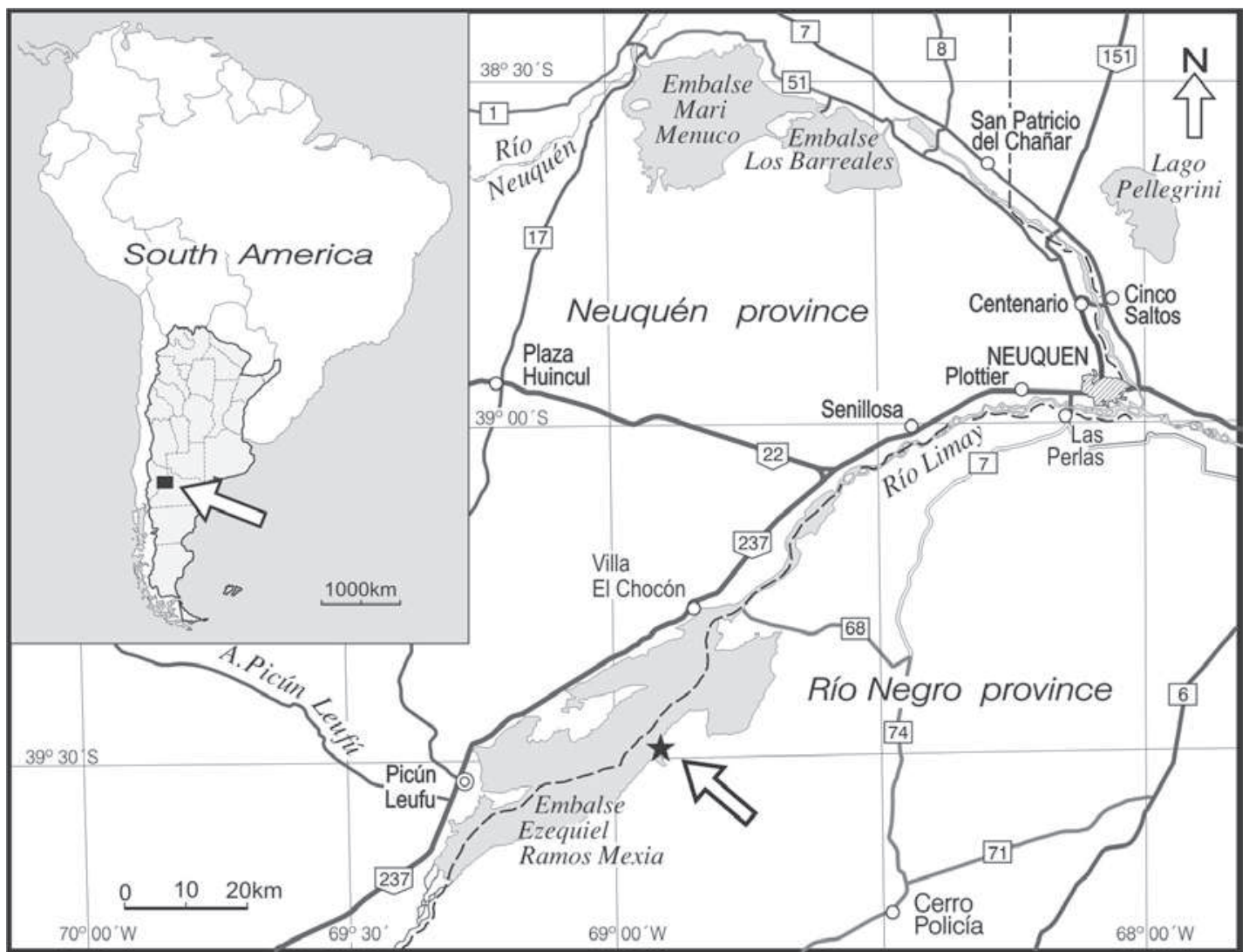

Fig. 1. Map showing the fossiliferous locality (star) where the holotype and paratypes of Bicentenaria argentina were found.

We interpret that both the holotype and paratype specimens belong to a single species for the following reasons: 1) duplicate hindlimb elements (e.g., femur, tibia, metatarsals, and pedal phalanges) possess an identical anatomy; 2) available bones exhibit theropod, tetanuran and coelurosaurian synapomorphies (these derived features are mentioned in the text below); and 3) there is no evidence of any other dinosaur taxon preserved in the quarry. Excepting for the fragmentary skull, the disarticulated nature of the assemblage avoids recognition of discrete specimens composed for more than a single bone.

\section{Cladistic analysis}

A phylogenetic numerical analysis was conducted to assess the phylogenetic relationships of Bicentenaria argentina among neotetanuran theropods. The data matrix was modified from that published by Zheng et al. (2009), in which the ingroup was focused on coelurosaurian theropods. The addition of ten operational taxonomic units (i.e., Tugulusaurus faciles Dong, 1973, Santanaraptor placidus Kellner, 1999, Nqwebasaurus thwazi De Clerk et al., 2000, Mirischia asymmetrica Naish et al., 2004, Aniksosaurus darwini Martínez \& Novas, 2006, Anchiornis huxleyi Xu et al., 2009a, Mahakala omnogovae Turner et al., 2007, Elaphrosaurus bambergi Janensch, 1920, Dilophosaurus wetherilli Welles, 1954 and Bicentenaria argentina nov. gen. et nov. sp.) and three characters resulted in a modified data matrix composed of 363 characters and 100 taxa. The basal neotheropod Dilophosaurus wetherilli (Welles, 1954) was used to root the recovered most parsimonious trees (MPTs). The data matrix was analyzed under equally weighted parsimony using TNT 1.1 (Goloboff et al.,2008). A heuristic search of 100 replications of Wagner trees (with random addition sequence) followed by TBR branch-swapping algorithm (holding 10 trees per replicate) was performed. The best trees obtained at the end 
of the replicates were subjected to a final round of TBR branch swapping. Zero length branches among any of the recovered MPTs were collapsed (i.e., rule 1 of Coddington \& Scharff, 1994). All multistate characters were treated as unordered and no a priori character polarization was used (see Appendixes 1-2).

\section{Analysis of body size evolution}

This analysis was conducted through the scoring of femoral lengths as a continuous character across the theropods sampled in the previously analyzed data matrix [measurements taken mostly from Benson et al. (2011); estimations of femoral length were followed only if they were calculated after ilium or hindlimb bone lengths and taxa represented solely by juvenile specimens were considered as missing data] (see Appendix). Subsequently, the character was optimized in the topology of each recovered MPT following a maximum parsimony criterion through which the ancestral femoral length ranges were obtained.

\section{SYSTEMATICS}

Theropoda Marsh, 1881

Tetanurae Gauthier, 1986

Coelurosauria Huene, 1920

\section{Bicentenaria argentina nov. gen. et nov. sp.}

Etymology. From bicentenary, due to the 200 years of the Revolution of May (25 ${ }^{\text {th }}$ May 1810), which lead to the first Argentinean autonomous government, thus constituting one of the most important chapters in the history of this South American country. Specific epithet honors Argentina, the country where the specimens were recovered.

Holotype. MPCA 865, caudal half of skull in articulation with the lower jaws (Fig. 2).

Paratypes. MPCA 866, around 130 bones, including fragments of two articulated premaxillae with three pairs of teeth, an incomplete right maxilla with a single tooth, fragments of seventeen dorsal vertebrae, fourteen sacral ver- tebrae, twenty caudal vertebrae, fragments of two scapulae, caudodorsal corner of a right coracoid, proximal ends of three ulnae, distal end of radius, eight manual unguals, fragments of left ilium, proximal fragments of five pubic shafts, five incomplete femora, proximal thirds of two left tibiae and distal end of the right one, right astragalus, fragments of five metatarsals, fifteen non-ungual pedal phalanges, eight pedal unguals, and several isolated rib fragments.

Locality and horizon. Upper levels of the Candeleros Formation (Cenomanian, early Late Cretaceous; Leanza et al., 2004), Río Limay Subgroup, Neuquén Group. The fossiliferous locality is placed at the east shore of Ezequiel Ramos Mexía Reservoir, Río Negro Province, Northern Patagonia, Argentina (Fig. 1). GPS coordinates of the fossil site are 39 $28^{\prime}$ 9.82" S, 68 $54^{\prime}$ '25.01" W. The rocks of the Candeleros Formation which yielded the remains of Bicentenaria argentina are made up by red medium sized sandstones and mudstones, with abundant dark-brownish paleosoils representing a fluvial environment under braided and meandering regimes, as well as in aeolian conditions (Leanza et al., 2004; Garrido, 2011).

Diagnosis. Bicentenaria argentina was a smallsized theropod ca. $3 \mathrm{~m}$ long [estimated by extrapolating bone measurements from the reconstructed skeletons of Compsognathus and Tanycolagreus; Ostrom, 1978; Carpenter et al., 2005)] and ca. $40 \mathrm{~kg}$ of body mass [following formula from Seebacher (2001)]. Bicentenaria argentina is diagnosed on the following autapomorphies: premaxillary teeth with mesial denticles only at the base of the crown; quadratojugal with a rostral process two times longer than the dorsal process; quadrate with lateral condyle much larger than the medial one; surangular with a raised dorsal margin trapezoidal-shaped in lateral profile; retroarticular process dorsoventrally depressed, transversely wide, and spoon-shaped; humerus with proximal end craniocaudally flattened, and distal end bearing a deep fossa on its cranial surface; and manual unguals of external digits bearing proximal dorsal lips.

Fig. 2. Selected cranial elements of Bicentenaria argentina nov. gen. et nov. sp. A, left lateral view of preserved caudal half of skull and jaws; $\mathbf{B}$, right lateral view of preserved caudal half of skull and jaws; $\mathbf{C}$, left quadrate and lower jaw in caudal view; $\mathbf{D}$, fragmentary premaxillae with teeth in left lateral view; $\mathbf{E}$, fragmentary left maxilla with tooth in lateral view. Abbreviations: an, angular; antf, antorbital fossa; art, articular; bs, basipterygoid process of basisphenoid; ch, notch for the chorda tympanica; gl, glenoid fossa; j, jugal; lc, lateral condyle of quadrate; lr, longitudinal ridge; ect, ectopterygoid; prar, right prearticular; pral, left prearticular; ptq, pterigoid ramus of quadrate; q, quadrate; qj, quadratojugal; sanl, left surangular; sanr, right surangular; rart, retroarticular process; $\mathbf{t}$, tooth. Scale bars $=1$ centimeter. 

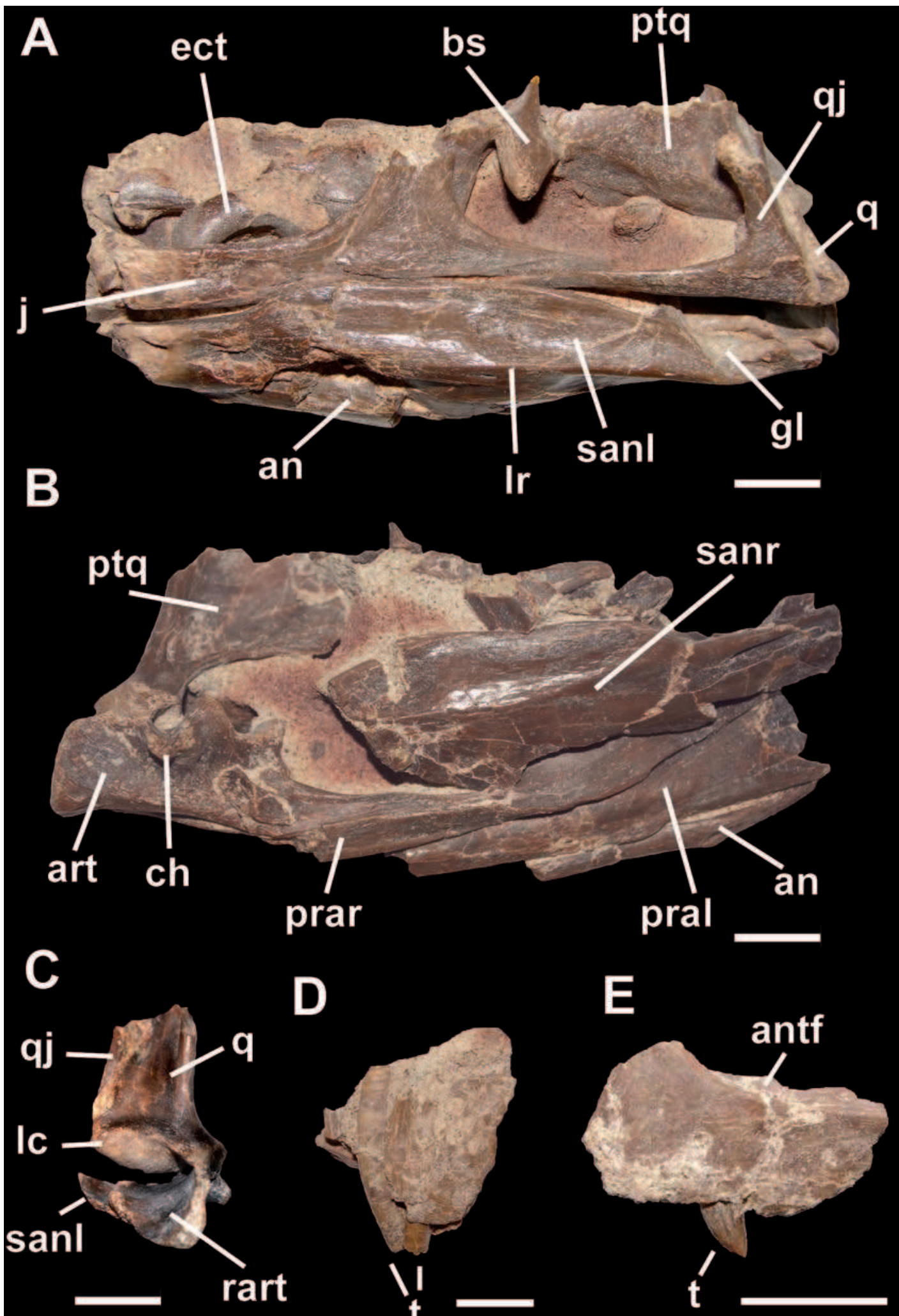

D
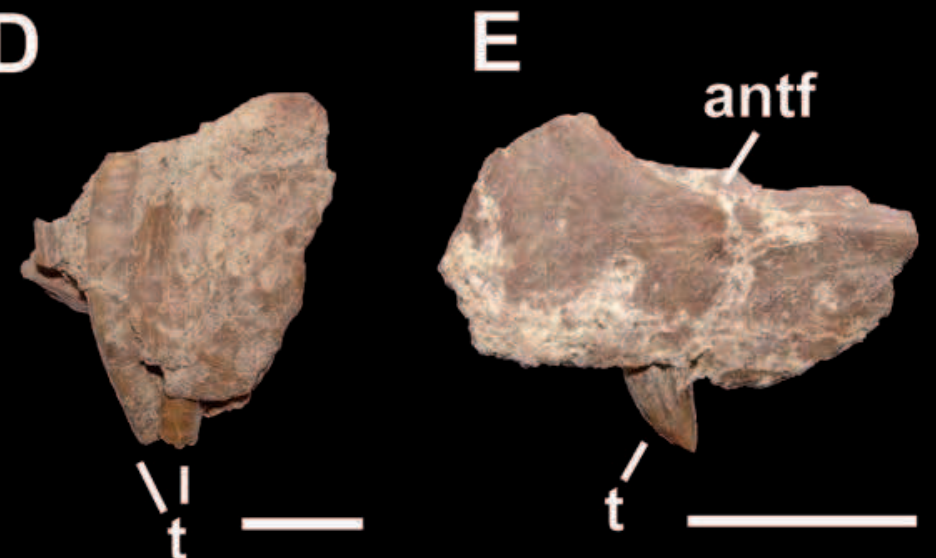
Description. The premaxillae of Bicentenaria bears at least four teeth, which are sub-circular in cross-section and mostly devoid of serrations at the distal and mesial margins of the crown. However, the second tooth of the right premaxilla possesses mesial denticles that are restricted to the basalmost portion of the crown. This morphology clearly departs from the "D"-shaped condition synapomorphic of tyrannosauroids (Rauhut et al., 2009).

The preserved maxilla presents a nearly smooth external surface and a row of proportionally large neurovascular foramina, aligned parallel to the alveolar margin. The only available maxillary tooth is highly labiolingually compressed, and exhibits serrated mesial and distal carinae up to the tip of the crown. The distal serrations are coarser than the mesial ones, as it occurs in other coelurosaurs (e.g., Zuolong, Ornitholestes, Velociraptor, Troodon; Choiniere et al., 2010; Currie et al., 1990).

The jugal is incompletely preserved, lacking its rostral process; the caudal process is bifurcated into two long and acute prongs for articulation with the quadratojugal. The jugal bears a flat and lateroventrally oriented facet for the contact of the surangular when the jaws were closed.

The quadratojugal exhibits an acute and elongate rostral process for articulation with jugal. Its length exceeds the dorsoventral height of the ascending process of the quadratojugal. This condition differs from the shorter rostral process seen in most coelurosaurs, including tyrannosauroids (e.g., Proceratosaurus, Tanycolagreus, Tarbosaurus; Currie, 2003; Carpenter et al., 2005; Rauhut et al., 2009), ornithomimids (e.g., Gallimimus; Osmólska et al., 1972), and compsognathids (e.g. Compsognathus; Ostrom, 1978). On the other hand, in Sinraptor and Monolophosaurus, this process is also rostrocaudally elongate, but constrasting with Bicentenaria in that in these two taxa the process is dorsoventrally thicker (Currie \& Zhao, 1993). The rostral process appears to be dorsoventrally high, as occurs in several theropods, including Proceratosaurus and Gallimimus (Rauhut et al., 2009; Osmólska et al., 1972). In Bicentenaria, both rostral and ascending processes of the quadratojugal describe an angle lesser than 90 degrees. The ascending ramus of quadratojugal is rostrocaudally thin, a condition that constrasts with the robust one in other basal coelurosaurs, such as tyrannosauroids (e.g. Tanycolagreus, Proceratosaurus; Carpenter et al., 2005; Rauhut et al., 2009) and ornithomimids (e.g., Gallimimus; Osmólska et al., 1972).

The quadrate exhibits a concave external edge and the quadrate foramen is small and proximally located, being very similar in proportion and morphology to that of Allosaurus (Madsen, 1976). The quadrate is a solid bone, lacking a caudal pneumatic diverticulum of the tympanic system, a condition exhibited by tyrannosaurids, ornithomimosaurs, troodontids, oviraptorids, and basal birds (Rauhut, 2003). The medial distal condyle of the quadrate is strongly reduced, being less than half the transverse width of the lateral condyle. Cranially, the quadrate exhibits a laminar and well-developed rostral process, a condition reminiscent to that present in Tanycolagreus (Carpenter et al., 2005).

The ectopterygoid is incompletely preserved and partially obscured by other cranial bones. Its preserved portion suggests that it possessed a well-developed, hook-like lateral process. Medially, it articulates with the poorly preserved pterygoid.

The braincase of Bicentenaria is represented only by the left basipterygoid process of the basisphenoid. The lateral surface of the basipterygoid process is excavated by a very deep and wide pneumatic recess, resembling the condition present in Stokesosaurus (Chure \& Madsen, 1998), for example. In tyrannosaurids and other coelurosaurs such recess on the basipterygoid process is much more reduced (Chure \& Madsen, 1998; Rauhut et al., 2009). The rostral and mid-portions of the mandibles are missing. The caudal half of both jaws is preserved, being somewhat distorted. The surangular shows on its rostral portion a deep notch, indicating the presence of a mandibular fenestra. The general contour of the bone, in lateral view, resembles that of Allosaurus (Madsen, 1976). However, its dorsal margin is more prominent, probably conforming an extended area for the insertion of the $M$. adductor mandibular externus (Currie $\&$ Zhao, 1993). The lateral surface of surangular shows a longitudinal shelf running below the glenoid cavity, as is also seen in other theropods (Sinraptor, Allosaurus, tyrannosaurids; Madsen, 1976; Currie \& Zhao, 1993; Currie, 2003). On the lateral surface of the surangular there is a wide and straited area for the articulation with the angular (this latter bone is partially broken and displaced from its natural position). The caudal end of the surangular is triangular and with a prominent dorsal process that encloses the glenoid cavity from behind. The caudal extension of 


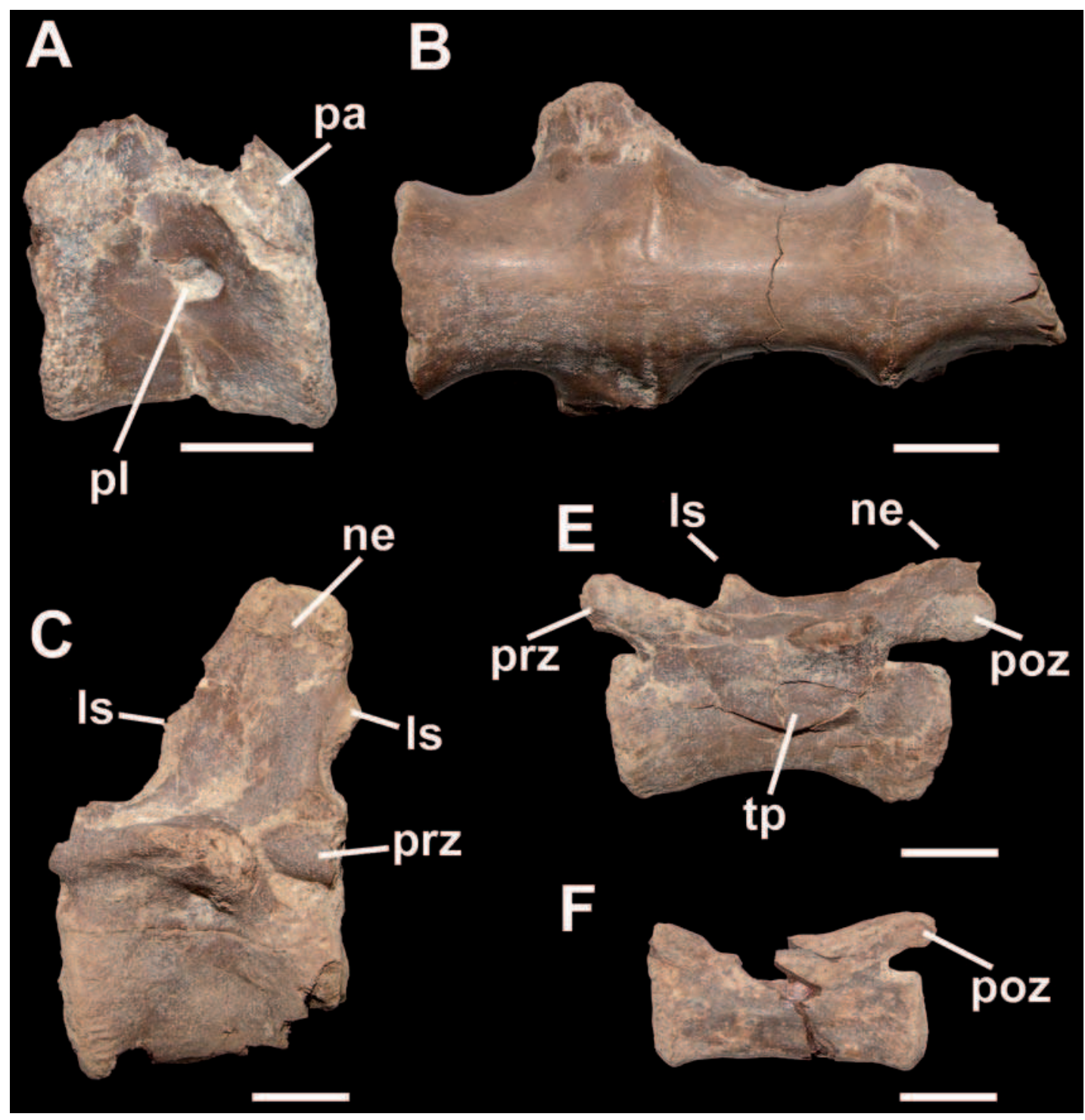

Fig. 3. Selected vertebral elements of Bicentenaria argentina nov. gen. et nov. sp. A, cranial dorsal centrum in right lateral view; B, partial sacrum in ventral view (cranial is towards the right); $\mathbf{C}$, proximal caudal vertebra in left lateral view; $\mathbf{D}$, distal caudal vertebra in left lateral view; $\mathbf{E}$, distal caudal vertebra in left lateral view. Abbreviations: ls, ligament scar; ne, neural spine; pa, parapophysis; pl, pleurocoel; poz, postzygapophysis; prz, prezygapophysis; $\mathbf{t p}$, transverse process. Scale bar $=1$ centimeter.

surangular behind the glenoid cavity resembles Allosaurus, being different from Compsognathus (Ostrom, 1978) in which the caudal end of the surangular extends further behind, and tyrannosaurids (Currie, 2003) in which the caudal end of the surangular is shorter and its caudal margin is subvertically oriented. In Bicentenaria the glenoid cavity is deeply excavated, apparently more than in Sinraptor and Allosaurus. The shape and size of the glenoid matches the morphology of the well-developed lateral articular condyle of the quadrate. The surangular portion of the glenoid is elliptical-shaped in dorsal view, with its largest axis rostromedially oriented. No signs of pneumaticity are detected in the articular, in contrast with the pneumatized condition seen in tyrannosauroids (Brusatte et al., 2010).

The left angular preserves its rostral end, bearing a conspicuous ventral elliptical depression that may have served for ligament attach- 
ment with the posteroventral process of dentary. The prearticular, instead, is a laminar bone that exhibits a laterally deflected lamina that wraps on the ventral margin of the angular.

The articular is large and robust and fits between the caudal ends of the surangular and prearticular. The retroarticular process of the articular is transversely wide, deeply concave, and mostly dorsally to caudodorsally oriented, conforming a spoon-shaped process similar to that in Ornitholestes hermanni (AMNH 619; Rauhut, 2003, fig. 21). The retroarticular process is separated from the glenoid fossa by a deep, transversely oriented ridge, as it is appreciated also in Allosaurus (USNM 4734) and Ornitholestes (AMNH 619). Medially, there is a prominent process dorsally notched, that served for the attachment of the chorda tympanica. This medially extended and dorsally notched process is also present in Sinraptor (Currie \& Chao, 1993), Allosaurus (USNM 4734) and Ornitholestes (AMNH 619), but it is absent in abelisaurids (Carnotaurus, Majungasaurus; Bonaparte et al., 1990; Sampson \& Witmer, 2007) and paravians (e.g., Deinonychus; Ostrom, 1969). In other words, Bicentenaria seems to have retained a basal tetanuran morphology for the caudal end of the jaw.

The vertebral column of Bicentaria is represented by several dorsal, sacral and caudal vertebrae belonging to different-sized individuals (Fig. 3). Two cranial dorsals (presumably dorsal vertebrae $? 3^{\text {rd }}$ and ?4th, based on general similarities with Allosaurus; Madsen, 1976), exhibit a sharp ventral keel and parapophyses located on the dorsal corner of centrum; a single pleurocoel perforates the centrum behind the parapophyses. The centrum of the presumed third dorsal has a slightly convex cranial articular surface and a deeply concave caudal surface. The centrum of the remaining dorsals is amphicoelous, and their ventral surfaces are flattened. Aside from the probable third dorsal vertebrae, the remaining available dorsals do not exhibit external pneumatic features. The broken portions of some centra reveal that the internal bone structure is of the camellate type (Benson et al., 2012). The proximal third of an isolated rib resembles the shape of ribs corresponding to the $1^{\text {st }}$ through $3^{\text {rd }}$ dorsal ribs of Allosaurus (Madsen, 1976).

Portions of eight sacra are available, six of which are represented by two to four fused centra (Fig. 3). We assume that the sacrum of Bicentenaria was originally composed by five vertebrae, as is usual in other basal tetanurans and coelurosaurians (e.g., Allosaurus, Tyrannosaurus: Madsen, 1976; Brochu, 2002). Each sacral centrum is robust and ventrally rounded in transverse section; towards the caudal end of the sacrum the vertebrae become stouter. Sacrals are devoid of external pneumatic features.

Several caudal vertebrae corresponding to different portions of the tail are available (Fig. 3). A proximal caudal vertebra, resembling the caudal $4^{\text {th }}$ of Allosaurus (Madsen, 1976), exhibits transverse processes that are ventrally excavated at their bases. The neural spine of this vertebra possesses ligament scars along both cranial and caudal margins, as it also occurs in Allosaurus (Madsen, 1976). The proximal caudal vertebrae bear tall and subdivided neural spines, resembling allosauroids (Madsen, 1976; Brusatte \& Sereno, 2008) and some basal coelurosaurs (e.g. Sinosauropteryx; Santanaraptor; Currie \& Chen, 2001; Kellner, 1999). The caudal vertebrae of Bicentenaria lack pleurocoels and exhibit a ventral sulcus bounded by two faint longitudinal ridges. Some isolated caudal vertebrae resemble caudals $19^{\text {th }}$ through $20^{\text {th }}$ of Allosaurus (Madsen, 1976). Most of the available distal caudals of Bicentenaria are damaged, and none of them preserves complete prezygapophyses. Thus, it is unknown if they possessed the elongate condition of most theropods.

The scapular girdle of Bicentenaria is represented by fragments of the proximal portions of the scapula and coracoid (Fig. 4). The glenoid fossa of the scapular girdle is large and wide, limited by a supraglenoid buttress. The proximal fragment of a left humerus and the distal extremes of both left and right humeri are preserved (Fig. 4). The proximal end is craniocaudally flattened, different from the cranially excavated condition of most theropods (e.g., Coelophysis, Allosaurus, Deinonychus; Madsen, 1976; Ostrom, 1969). The internal tuberosity is

Fig. 4. Selected scapular girdle and forelimb elements of Bicentenaria argentina nov. gen. et nov. sp. Right humerus. $\mathbf{A}$, cranial view of proximal end; $\mathbf{B}$, caudal view of proximal end; $\mathbf{C}$, cranial view of distal end; $\mathbf{D}$, caudal view of distal end; E, distal view; F, proximal view; $\mathbf{G}$, fragmentary left scapula and coracoid in lateral view; $\mathbf{H}$, manual ungual of digit I or II; I, manual ungual probably of digit III. Abbreviations: cor, coracoid; en, entepicondyle; f, fossa; gl, glenoid cavity; h, humeral head; it, internal tuberosity; pdl, proximodorsal lip; rc, radial condyle; sc, scapula; uc, ulnar condyle. Scale bar $=1$ centimeter. 


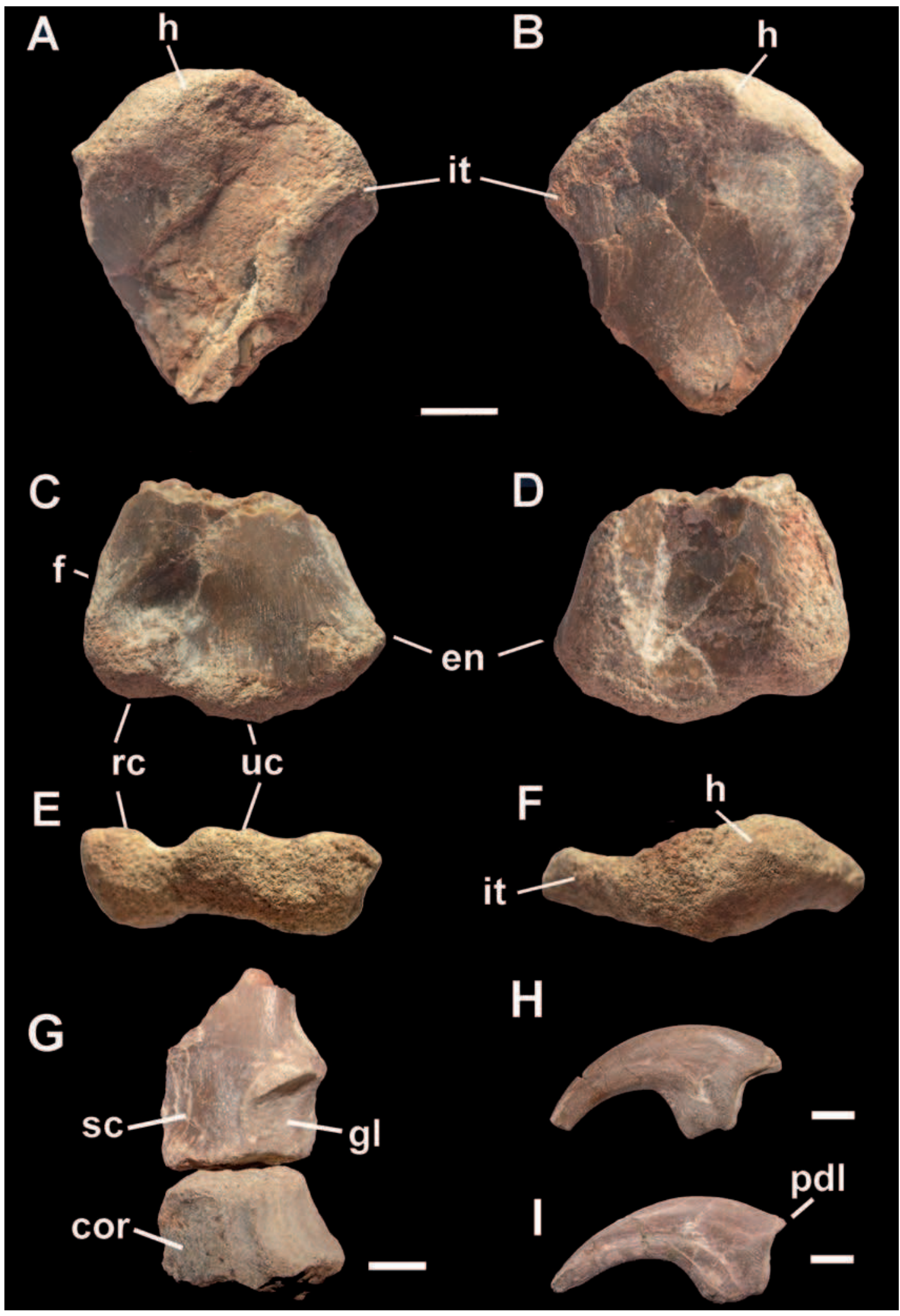


subtriangular in cranial aspect. The proximal articular head is kidney-shaped, being caudally convex and cranially concave. The slender morphology of the preserved portion of the proximal humerus contrasts with the robustness of the scapular girdle. Notably, the cranial surface of the distal humerus bears a deep and rounded fossa above the radial condyle. The distal articular condyles of the humerus are poorly defined, but the entepicondyle is prominent. The ulna bears a poorly developed olecranon process. The manual unguals are trenchant and transversely compressed; the larger ones are interpreted as belonging to digit first (Fig. 4). Some smaller unguals possess a proximodorsal lip and a prominent ventral flexor tubercle, which are here recognized as corresponding to the third manual digit. Proximal dorsal lips are absent in manual unguals of compsognathids and Ornitholestes, but they are present in some derived coelurosaurs such as oviraptorosaurs and paravians (Novas et al., 2005), as well as in some basal taxa, including Tanycolagreus and Guanlong (Carpenter et al., 2005; Xu et al., 2006). However, due to the restricted distribution of this feature among coelurosaurs, we assume that the presence of dorsal lips in some of the manual unguals of Bicentenaria may constitute an autapomorphic trait of this taxon.

The ilium of Bicentenaria exhibits a prominent but faintly laterally projected supraacetabular crest (Fig. 5). The brevis fossa is transversely narrow. The brevis shelf is strongly developed and projects ventromedially as in Allosaurus (Madsen, 1976), but differs from Aniksosaurus in which this shelf is flaring outwards (Martinez \& Novas 2006). A large portion of a right pubic shaft is available, which preserves the base of the pubic tubercle (i.e., the ambiens process) and resembles the condition observed in many other theropods (e.g., Sinraptor, Allosaurus, Gallimimus, Aerosteon; Osmólska et al., 1972; Madsen, 1976; Currie \& Zhao, 1993; Sereno et al., 2008). The medial flange of the pubic shaft (the pubic apron) originates as a low but sharp ridge on the caudo-medial margin of pubis, at level of the ambiens process. This flange becomes much more prominent cranially and distally, resembling the condition of Allosaurus (Madsen, 1976). Although the proximal end of the preserved pubis is incomplete, the similarities with Allosaurus suggest that the obturator foramen of Bicentenaria was ventrally open.

The femur of Bicentenaria is long and slender (a composite restoration indicates a maximum length of approximately $31 \mathrm{~cm}$ ), differing from the robust condition of basal tetanurans (e.g., Allosaurus; Madsen, 1976) and Aniksosaurus (Martínez \& Novas, 2006). The femur of Bicentenaria (Fig. 5) has a craniomedially-oriented head, bearing a deep posteromedial sulcus for the passage of the Lig. capitis femoris. The anterior trochanter is damaged in all available femora, but a wing-shaped condition is inferred based on the craniocaudally expanded condition of its base. The anterior trochanter is separated from the femoral head by a deep cleft. A strongly developed bulge, presumably homologous to the trochanteric shelf of more basal dinosaurs (Novas, 1996), is present laterodistally to the anterior trochanter. The fourth trochanter is reduced to a proximodistally extended ridge, but its corresponding medial scar for the attachment of the $M$. caudifemoralis brevis is deep. The distal femur presents a well-developed mediodistal crest, bounding a deep longitudinal medial depression, as occurs in most basal neotheropods (e.g. "Syntarsus" kayentakatae; Ceratosaurus; Allosaurus; Rowe, 1989; Gilmore, 1920; Madsen 1976) and some basal coelurosaurs (e.g., Tyrannosaurus; Brochu, 2002). Distally, the femur exhibits a markedly deep extensor groove. The tibia exhibits a cnemial crest that is proximodistally short and slightly projected cranially, as it occurs in other coelurosaurians (Rauhut, 2003). The lateral condyle of proximal tibia is prominent, but it is craniocaudally shorter than in Allosaurus (Madsen, 1976). The distal end of tibia presents a square-shaped internal malleolus. The facet for the reception of the ascending process of the astragalus is almost inexistent, as in most coelurosaurs (Rauhut, 2003, 2005).

The astragalus (Fig. 6) exhibits a large and rounded medial condyle, which is separated from the lateral one by a median constriction of the astragalar body. The ascending process is restricted to the lateral half of the astragalar body, resembling the condition of non-coelurosaurian theropods as well as basal coelurosars, such as Tugulusaurus (Rauhut \& Xu, 2005). By contrast, more derived coelurosaurians exhibit an ascending process transversely expanded for most of the transverse width of the astragalus (Long \& Welles, 1974; Rauhut, 2003). The preserved pedal bones of Bicentenaria are gracile and metatarsals III and IV, at least, lack a ginglymous distal end. The first metatarsal is reduced to a splint-like bone. The pedal ungual phalanges are acute and poorly curved, with subtriangular proximal ends (Fig. 5). 


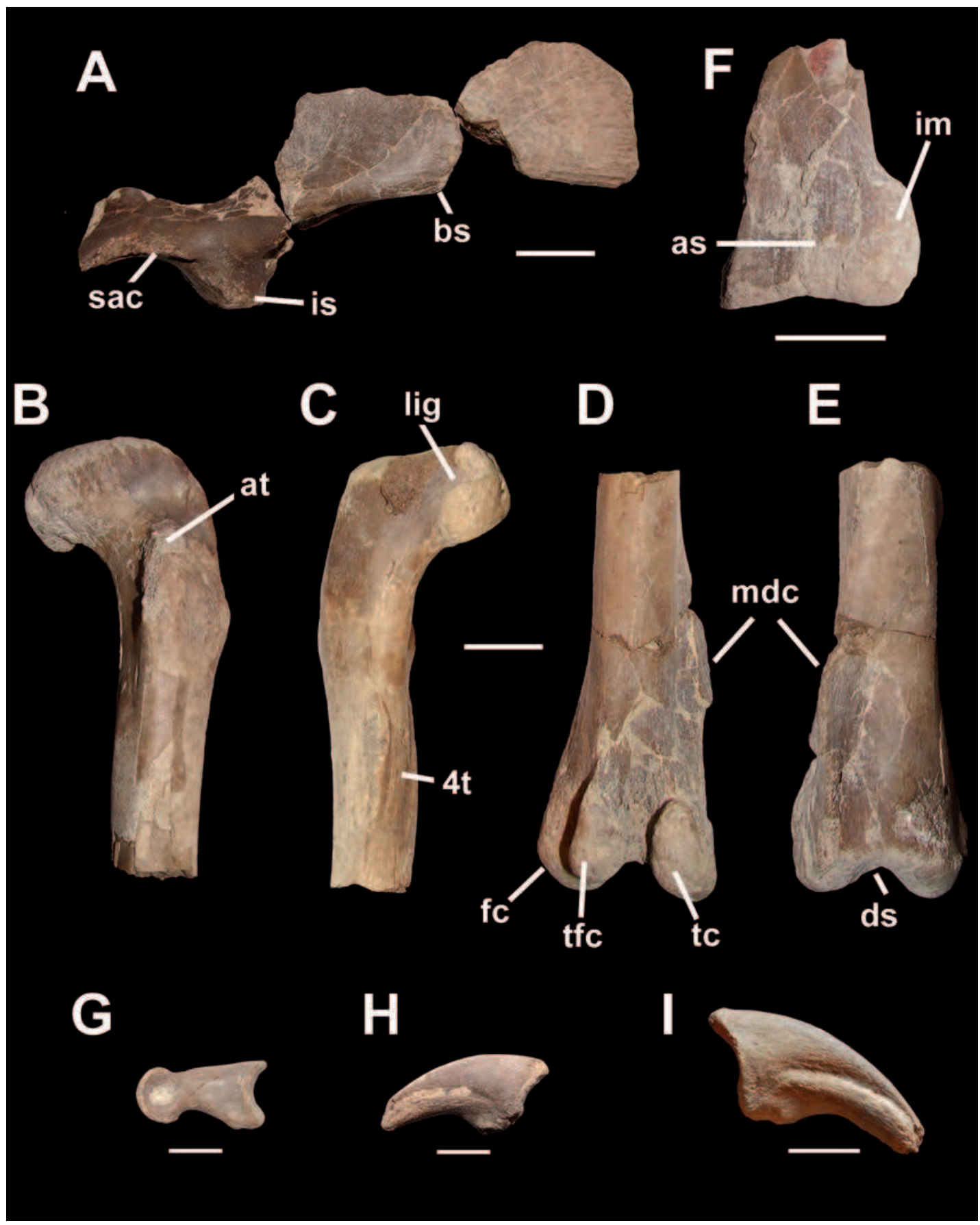

Fig. 5. Selected pelvic girdle and hindlimb elements of Bicentenaria argentina nov. gen. et nov. sp. A, left ilium in lateral view; B,C, proximal end of left femur in $\mathbf{B}$, cranial and $\mathbf{C}$, caudal views; $\mathbf{D}, \mathbf{E}$, distal end of left femur in $\mathbf{D}$, caudal and $\mathbf{E}$, cranial views; $\mathbf{F}$, distal end of right tibia in cranial view; $\mathbf{G}$, non-ungual pedal phalanx in lateral view; H, pedal ungual phalanx of digit VI in lateral view; I, pedal ungual phalanx of digits II or III in lateral view. Abbreviations: as, articular surface for the ascending astragalar process; at, anterior trochanter; bs, brevis shelf; ds, distal sulcus; 4t, fourth trochanter; im, inner malleolus; is, ischiac pedicle; lig, ligament sulcus; mdc, mediodistal crest; sac, supracetabular crest; tc, tibial condyle; tfc, tibiofibular condyle. Scale bar: A-F = 2 centimeters; $\mathbf{G - I}=1$ centimeter. 


\section{DISCUSSION}

Bicentenaria argentina comes from the Candeleros Formation which yielded other theropod dinosaurs such as the carcharodontosaurid Giganotosaurus carolini (Coria \& Salgado 1995), the abelisaurid Ekrixinatosaurus novasi (Calvo et al., 2004), and the unenlagiid Buiteraptor gonzalezorum (Makovicky et al., 2005). Bicentenaria clearly differs from the first two taxa in being a much smaller animal of gracile construction, devoid of the synapomorphies characterizing carcharodontontosaurids and abelisaurids. Besides, Bicentenaria lacks the highly derived, avian-like features, present in the paravian coelurosaur Buitreraptor.

In South America, another sedimentary unit that yielded a similar dinosaur fauna of Cenomanian age is the Lower Bajo Barreal Formation, cropping out in central Patagonia (Novas, 2009). The Lower Bajo Barreal Formation yielded the remains of the basal coelurosaur Aniksosaurus darwini (Martínez \& Novas, 2006), with a body size somewhat smaller than its roughly coeval Bicentenaria. Nevertheless, Aniksosaurus differs from the latter one in having limb bones proportionally more robust, especially regarding the humerus and femur. The ilium of Aniksosaurus clearly differs from Bicentenaria in having a greatly expanded and flaring outwards brevis shelf (Martínez \& Novas, 2006). The femur of Aniksosaurus differs from that of Bicentenaria in lacking a welldeveloped mediodistal crest, and a deep posteromedial sulcus for the passage of the Lig. capitis femoris. The tibia of Aniksosaurus plesiomorphically retained a transverse ridge for the articulation with the ascending process of the astragalus, a condition that is absent in Bicentenaria. Moreover, Aniksosaurus exhibits some features that may support sister-group relationships with the clade made up by Ornithomimosauria plus Maniraptoriformes (e.g., caudally divergent postacetabular iliac blades; undivided neural spines of caudal vertebrae). In other words, Bicentenaria and Aniksosaurus are not closely related each other, but constitute representatives of different lineages of basal coelurosaurians that inhabited Patagonia during Cenomanian times.

Another South American theropod that deserves some comparisons with Bicentenaria is the Aptian Santanaraptor, from the Santana Formation of NE Brazil (Kellner, 1999). At first glance, both taxa resemble in the long and slender proportions of the femur, in the common presence of a deep posteromedial sulcus for the passage of the Lig. capitis femoris, and that the proximal caudals presents tall and subdivided neural spines. However, several differences allow distinguish Bicentenaria from the Brazilian form. For example, available bones of Santanaraptor are considerable smaller and more gracile than those of Bicentenaria; the femur of Santanaraptor is devoid of fourth trochanter and the mediodistal crest is absent (Kellner, 1999). In Santanaraptor the distal end of tibia is much more compressed craniocaudally than in Bicentenaria, and the internal malleolus of tibia lacks the squareshaped contour in cranial view described for Bicentenaria. In Santanaraptor the astragalus exhibits some traits that are more derived than in Bicentenaria: the ascending process is dorsoventrally extended and transversely wide, and the caudal process of the astragalar body is much less developed than in the Patagonian form.

Based on the comparisons made above, Bicentenaria results clearly distinguishable from other known basal coelurosaurs from the Cretaceous of South America. With the aim to assess the phylogenetic position of Bicentenaria among basal coelurosaurs, we performed a phylogenetic cladistic analysis (see Materials and Methods), the results of which were 1388 most parsimonious trees of 2886 steps, with a consistency index of 0.321 and a retention index of 0.753. Optimal trees were found 50 times of the total of 100 replications. The strict consensus tree depicts a large polytomy close to the base of Coelurosauria, but the main lineages within this clade are relatively well-resolved. However, the lack of resolution close to the base of Coelurosauria is mostly a consequence of a single wild-card taxon, the enigmatic South American coelurosaur Santanaraptor. This taxon is found alternatively as a very basal tyrannosauroid or as a basal maniraptoriform. After an a posteriori pruning of Santanaraptor, the strict reduced consensus depicts a well-resolved overall topology, but some polytomies are still present in nodes deeply nested within Compsognathidae and at the base of Maniraptoriformes among basal coelurosaurs (Fig. 7). Bicentenaria argentina was found as a very basal coelurosaur, placed between the archaic allosauroids and the lineage leading to the avian radiation. The Chinese theropod Tugulusaurus was found as the most basal coelurosaur, a result that is congruent with the hypothesis proposed by Rauhut \& Xu (2005). The basal position of Tugulusaurus within Coelurosauria is supported by the retention of a 


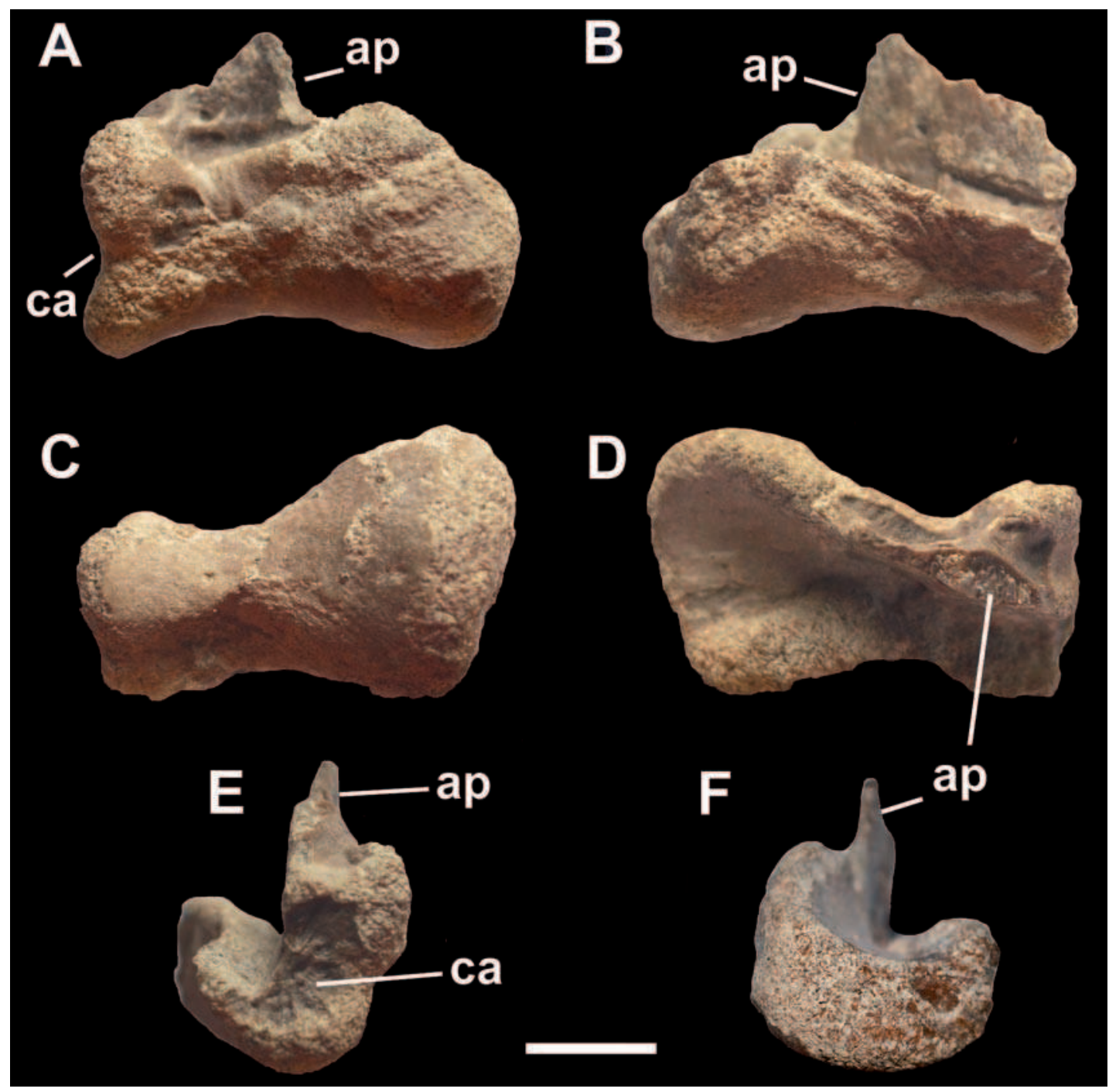

Fig. 6. Right astragalus Bicentenaria argentina nov. gen. et nov. sp. A, cranial view; B, caudal view; $\mathbf{C}$, distal view; D, proximal view; E, lateral view; F, medial view. Abbreviations: ap, ascending process; ca, articular surface for calcaneum. Scale bar $=1$ centimeter.

symplesiomorphic distal end of tibia with a wellrimmed facet for the reception of the ascending process of astragalus, contrasting with the condition observed in Bicentenaria and all other coelurosaurs, in which this facet is absent (except Aniksosaurus). The coelurosaurs more derived than Tugulusaurus, including Bicentenaria, share apomorphic maxillary tooth crowns with increased density of denticles along the mesial margin, pubis with a transversely compressed distal end, and a distal end of the tibia without well-defined borders of the facet for the reception of the ascending process of the astragalus (the condition of the first two characters is unknown in Tugulusaurus). However, Bicentenaria lacks the synapomorphies present in more derived coelurosaurians, supporting the basal position hypothesized for the new Patagonian taxon. The synapomorphies that are shared by the coelurosaurs more derived than Bicentenaria include: quadratojugal with a rostral process shorter than the dorsal one, caudal vertebrae with undivided neural spines, distal end of femur without a mediodistal crest (apomorphically reversed in tyrannosaurids), and astragalus with a transversely broad and tall ascending process. 


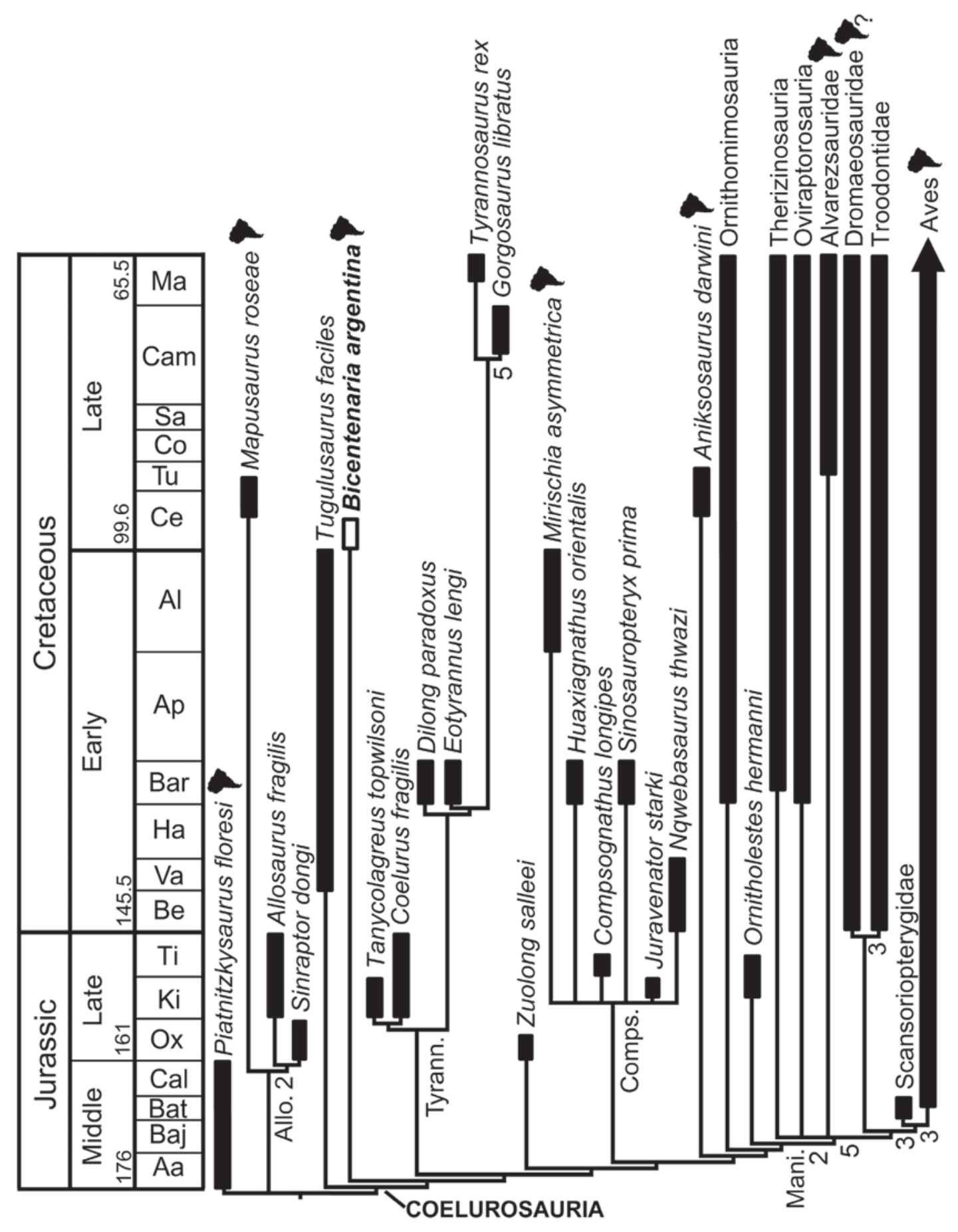

Fig. 7. Simplified strict reduced consensus cladogram after the a posteriori pruning of Santanaraptor indicating the phylogenetic relationships of Bicentenaria argentina. The numbers below the nodes are Bremer values greater than 1. 


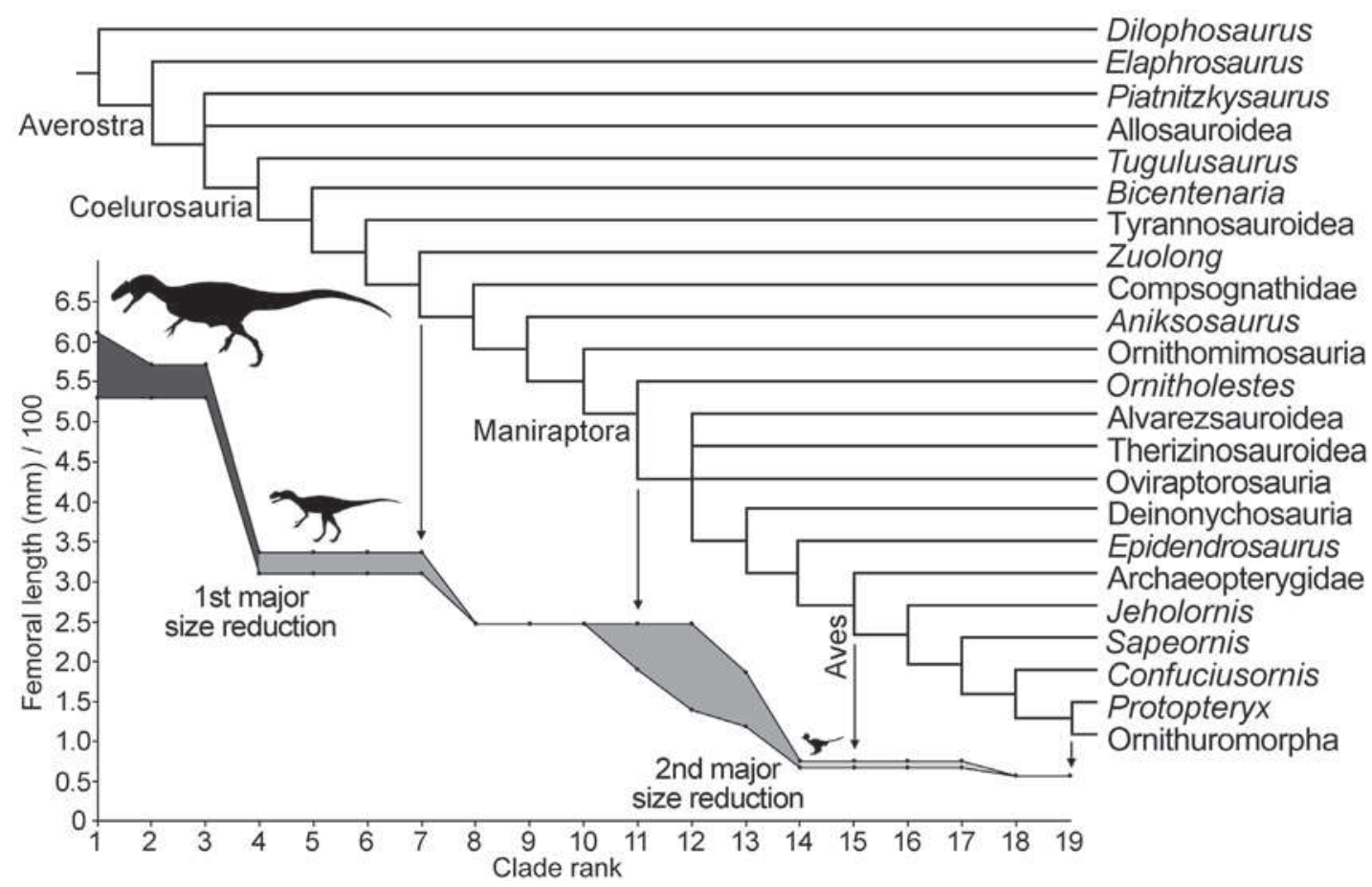

Fig. 8. Body size evolution through basal therpopod phylogeny after the optimization of femoral length as a continuous character in each MPT recovered. The graphic at the bottom shows the ancestral reconstruction of femoral length (in $\mathrm{mm}$ ) / 100 against clade rank for each stem node represented in the theropod phylogeny (above).

In the present analysis, the Brazilian Mirischia (Naish et al., 2004) and the South African Nqwebasaurus (De Clerk et al., 2000) are nested within Compsognathidae, indicating a cosmopolitan distribution for this family during, at least, the Early Cretaceous. The problematic Brazilian Santanaraptor (Kellner, 1999) is here recovered as an indeterminate basal coelurosaur, while the South American Aniksosaurus is found as the sister-taxon of the clade including Ornithomimosauria and Maniraptoriformes. Accordingly, the results of our phylogenetic analysis indicate the presence of, at least, four different lineages of basal Gondwanan coelurosaurs, with their ghost lineages extending back to the Middle and Late Jurassic. Thus, a previously unexpected high taxonomic diversity of basal coelurosaurs appears to have inhabited Gondwana during the Cretaceous. Particularly, in the case of Bicentenaria argentina and Aniksosaurus darwini, we hypothesize extensive ghost lineages of about 70 millions of years. These extensive ghost lineages are in agreement with the remarkable anatomical specializations recognized for each of these almost coeval species.

Bicentenaria exhibits a size approaching $3 \mathrm{~m}$ long and elongate and gracile hindlimb bones, an overall morphology reminiscent to that of some basals coelurosaurs, such as Tanycolagreus, Coelurus, Ornitholestes, Aniksosaurus, and Santanaraptor, among other taxa. The largest femora of Bicentenaria (approximate length $31 \mathrm{~cm}$ ) indicate that this taxon achieved a body length of about 3 meters and a body mass of 40 $\mathrm{kg}$ [calculated by extrapolating measurements of the basal coelurosaurs Compsognathus and Tanycolagreus, and employing equation applied by Seebacher (2001)]. The presence of closed neurocentral sutures in the vertebrae belonging to the large-sized individuals suggests that the available larger individuals of Bicentenaria were not juveniles, at least (Brochu, 1996; Irmis, 2007). The body length of Bicentenaria resembles that observed in other basal coelurosaurs, such as Tanycolagreus (femur length of 35.6 $\mathrm{cm}$; Carpenter et al., 2005a), Zuolong (femur length of $33.6 \mathrm{~cm}$; Choiniere et al., 2010), and Aniksosaurus (femur length of $24.7 \mathrm{~cm}$; Martínez \& Novas, 2006). The body size of all these basal coelurosaurs is considerably smaller than those of non-coelurosaurian averostrans, such as ceratosaurians, spinosauroids, and allosauroids. In 
this regard, the whole clade Coelurosauria was characterized by a size-decrease trend (Carrano, 2006). With the aim to explore size-trend evolution in Coelurosauria, we optimized femoral length as a proxi of body size, and this trait was considered as a continuous character in our strict reduced consensus tree (see Materials and Methods). As a result, two main episodes of drastic size reduction are identified in the evolutionary history of the group (Fig. 8). In basal averostrans (i.e., ceratosaurians, spinosauroids, and allosauroids) it was reconstructed an ancestral femoral length of 57.0-52.9 cm which conspicuously drop downs to a femoral length of 33.6$31.0 \mathrm{~cm}$ in basal coelurosaurs (e.g., Bicentenaria, Zuolong, Aniksosaurus), conforming a first major reduction in the body size (Fig. 8). The reduction in body size of coelurosaurs would have allowed adult forms to exploit ecological niches not occupied by larger basal averostrans. A first step of miniaturization in the coelurosaurian lineage would have resulted in lower generational times and higher rates of evolutionary change. This hypothesis would explain, at least in part, the extraordinary radiation observed among coelurosaurs during the Middle and Late Jurassic.

The ancestral body size of the coelurosaurs faintly decreased gradually towards the avian lineage up to a femoral length of 24.7-1.39 cm in the Therizinosauroidea + Alverezsauridae + Oviraptorosauria + Paraves clade. By coupling the previous results with those recovered by Turner et al., (2007), it becomes apparent that a second drastic decrease in body size took place at the Paraves-Avialae transition (Fig. 8), reaching in Avialae an ancestral femoral length of $0.75-0.67 \mathrm{~cm}$. The remarkable body size reduction observed at the base of Coelurosauria represents an evolutionary event preceeding body size miniaturization reported for derived paravians (Turner et al., 2007), involving a reduction of about 30 times with respect to more basal tetanuran taxa. Accordingly, the miniaturization of body size that benefited birds to develop flying capabilities (Novas \& Puerta, 1997; Turner et al., 2007) seems to have occurred in an apparent twostep pattern of size reduction in theropod evolution: a first one at the base of Coelurosauria, and a second one at the base of Avialae or its most immediate sister-taxa (i.e., Paraves; Turner et al., 2007).

The fact that Bicentenaria is known from several specimens corresponding to different ontogenetic stages, and that they were found together in a reduced fossil spot, leads to the interpretation that this taxon had gregarious behaviour, at least at the time of their death. The discovery of multiple individuals in a single monospecific quarry (interpreted as indicative of gregarious habits) have been usually documented among non-avian theropods (Horner, 1997), being present in at least seven non-avian theropod taxa: coelophysoids (Colbert, 1990), ceratosaurians (Xu et al., 2009), carcharodontosaurids (Coria \& Currie, 2006), Aniksosaurus (Martínez \& Novas, 2006), tyrannosauroids (Currie, 2000; Eberth \& McCrea, 2002), ornithomimosaurids (Kobayashi \& Lü, 2003), troodontids (Varricchio, 1995), and dromaeosaurids (Roach \& Brinkman, 2007). Thus, based on available evidence, a gregarious behaviour seems to represent an ancestral ethological condition for Theropoda, if not Dinosauria as a whole.

\section{CONCLUSIONS}

The discovery of Bicentenaria argentina increases the taxonomic diversity and morphological disparity of Gondwanan coelurosaurs, indicating that this supercontinent was a cradle for the evolutionary radiation of basal members of the clade. The transition between archaic theropods (i.e., basal averostrans) and the avian lineage (i.e., Coelurosauria) is spotted as one of the most interesting episodes of dinosaur macroevolution (Brusatte \& Sereno, 2008; Holtz, 2004) and the description of Bicentenaria adds more information about such evolutionary transition. In particular, the new discovery lends support to the hypothesis that a notable reduction in body size occurred early in the evolution of Coelurosauria, thus preceeding the remarkable miniaturization documented among paravian coelurosaurs. Size reduction may have played an important role in the evolutionary diversification of coelurosaurs as a whole.

\section{ACKNOWLEDGMENTS}

We deeply thank Mr. Raul Spedale for sharing his discovery. N.R. Chimento, M.R. Derguy, S.O. Lucero and G. Lio for their help during the elaboration of the present manuscript. M. Isasi prepared part of the available skeletal material. FEN thanks to CONICET and Agencia Nacional de Promoción Científica y Técnica (Buenos Aires) for their continuous support of our research and explorations (grants ANPCyT-PICTs 2006-58 and 2010-66). MDE acknowledges that this research was completed during receipt of $\mathrm{PhD}$ fund- 
ing from the Emmy Noether Programme of the DFG (grant BU 2587/3-1 to Richard Butler). N. Chimento helped with the confection of figures. Reviews by Steve Brusatte and Leonardo Salgado improved the overall quality of this paper.

\section{BIBLIOGRAPHY}

Benson, R.B.J., R.J. Butler, M.T. Carrano \& P.M. O'Connor. 2011. Air-filled postcranial bones in theropod dinosaurs: physiological implications and the 'reptile'-bird transition. Biol. Rev. 87: 168-193.

Benson, R.B.J., M.T. Carrano \& S.L. Brusatte. 2010. A new clade of archaic large- bodied predatory dinosaurs (Theropoda: Allosauroidea) that survived to the latest Mesozoic. Naturwissenschaften, 97: 7178.

Bonaparte, J.F., F.E. Novas \& R. Coria. 1990. Carnotaurus sastrei Bonaparte, the horned, lightly built carnosaur from the early Late Cretaceous of Patagonia. Contribution in Science, Natural History Museum of Los Angeles, 416:1-42.

Brochu, C.A. 1996. Closure of neurocentral sutures during crocodilian ontogeny: implications for maturity assessment in fossil archosaurs. J. Vert. Paleont. 16:49-62.

Brochu, C.A. 2002. Osteology of Tyrannosaurus rex: Insights from a nearly complete skeleton and highresolution computed tomographic analysis of the skull. Mem. Soc. Vert. Paleont. 7: 1-138.

Brusatte, S.L. \& P.C. Sereno. 2008. Phylogeny of Allosauroidea (Dinosauria: Theropoda): comparative analysis and resolution. J. Syst. Paleont. 6: 155-182.

Brusatte, S.L.; M.A. Norell, T.D. Carr, G.M. Erickson, J.R. Hutchinson, A.M. Balanoff, G.S. Bever, J.N. Choiniere, P.J. Makovicky \& X. Xu. 2010. Tyrannosaur paleobiology: new research on ancient exemplar organisms. Science 329: 1481-1485.

Calvo, J.O., D. Rubilar-Rogers \& K. Moreno. 2004. A new Abelisauridae (Dinosauria: Theropoda) from northwestern Patagonia. Ameghiniana, 41: 555563.

Carpenter, K., C. Miles \& K. Cloward. 2005. New small theropod from the Upper Jurassic Morrison Formation of Wyoming. En: K. Carpenter (Ed), The Carnivorous Dinosaurs. Indiana, Indiana University Press, pp 23-48.

Carrano, M.T. 2006. Body-size evolution in the Dinosauria. En: T. Carrano Matthew, T.J. Gaudin, R.W. Blob \& J.R. Wible (Eds.), Amniote Paleobiology: Perspectives on the Evolution of Mammals, Birds, and Reptiles. University of Chicago Press. pp.225268.

Choiniere, J.N., J.M. Clark, C.A. Forster \& X. Xu. 2010. A basal coelurosaur (Dinosauria: Theropoda) from the Late Jurassic (Oxofordian) of the Shishugou Formation in Wucaiwan, People's Republic of China. J. Vert. Paleont., 30: 1773-1796.

Chure, D.J. \& J.H. Madsen. 1998. An unusual braincase (?Stokesosaurus clevelandi) from the Cleeveland-
Lloyd Dinosaur Quarry, Utah (Morrison Formation: Late Jurassic). J. Vert. Paleont., 18: 115-125.

Coddington, J.A. \& N. Scharff. 1994. Problems with Zero-Length Branches. Cladistics 10: 415-423.

Colbert, E.H. 1990. Variation in Coelophysis bauri. En: K. Carpenter \& P.J. Currie (Eds.), Dinosaur systematics: approaches and perpectives. New York: Cambridge University Press, pp. 81-90.

Coria, R.A. \& P.J. Currie. 2006. A new carcharodontosaurid (Dinosauria, Theropoda) from the Upper Cretaceous of Argentina. Geodiversitas, 28: 71118.

Coria, R.A. \& L. Salgado. 1995. A new giant carnivorous dinosaur from the Cretaceous of Patagonia. Nature, 377: 224-226

Currie, P.J. 2000. Possible evidence of gregarious behavior in tyrannosaurids. GAIA, 15: 271-277.

Currie, P.J. 2003. Cranial anatomy of tyrannosaurids from the Late Cretaceous of Alberta, Canada. Acta Palaeont. Pol. 48: 191-226.

Currie, P.J. \& P.J. Chen. 2001. Anatomy of Sinosauropteryx prima from Liaoning, northeastern China. Can. J. Earth Sci., 38: 705-727.

Currie, P.J. \& X.J. Zhao. 1993. A new carnosaur (Dinosauria, Theropoda) from the Jurassic of Xinjiang, People's Republic of China. Can. J. Earth Sci. 30:2037-2081.

Currie, P.J., J.K. Rigby \& R.E. Sloan. 1990. Theropod teeth from the Judith River Formation of southern Alberta, Canada. En: K. Carpenter \& P.J. Currie (Eds.) Dinosaur systematics: Approaches and perspectives, pp. 107-125. Cambridge, Cambridge University Press.

De Clerk, W.J., C.A. Forster, S.D. Sampson, A. Chinsamy \& C.F. Ross. 2000. A new coelurosaurian dinosaur from the Early Cretaceous of South Africa. J. Vert. Paleont. 20: 324-332.

Dong, Z. 1973. Dinosaurs from Wuerho. Mem. Inst. Vert. Paleont. Paleoanthrop. Acad. Sinica, 11: 4552.

Eberth, D.A. \& R.T. McCrea. 2002. Were large theropods normally gregarious? Fossils 2002: Alberta Paleont. Soc. Abs.Vol.: 13-15.

Garrido, A.C. 2011. Estratigrafía del Grupo Neuquén, Cretácico Superior de la Cuenca Neuquina (Argentina): nueva propuesta de ordenamiento litoestratigráfico. Rev. Mus. Arg. Cienc. Nat., 12: 121-177.

Gilmore, C.W. 1920. Osteology of the carnivorous Dinosauria in the United States National Museum, with special reference to the genera Antrodemus (Allosaurus) and Ceratosaurus. Bulletin of the United States National Museum, 110: 1-154.

Goloboff, P.A., J.S. Farris \& K. Nixon. 2008. TNT, a free program for phylogenetic analysis. Cladistics 24: 774-786.

Holtz, T.R. 2004. Tyrannosauroidea. En: D.B. Weishampel, P. Dodson \& H. Osmolska (Eds.), The Dinosauria, Second Edition. Berkeley: California University Press, pp. 111-136.

Horner, J.R. 1997. Behavior. En: P.J. Currie \& K. Padian (Eds.), Encyclopedia of dinosaurs. Elsevier 
Academic press, pp 45-50.

Irmis, R.B. 2007. Axial skeleton ontogeny in the Parasuchia (Archosauria: Pseudosuchia) and its implications for ontogenetic determination in archosaurs. J. Vert. Paleont. 27: 350-361.

Janensch, W. 1920. Ueber Elaphrosaurus bambergi und die Megalosaurier aus den Tendaguru Schichten Deutsch-Ostafrikas. Sitz.-Ber. naturforsch. Fr. Berlin 1920: 225-235.

Kellner, A.W.A. 1999. Short note on a new dinosaur (Theropoda Coelurosauria) from the Santana Formation (Romualdo Member, Albian), Northeastern Brasil. Bol. Mus. Nac. Geol. 49: 1-8.

Kobayashi, Y. \& J.C. Lü. 2003. A new ornithomimid dinosaur with gregarious habits from the Late Cretaceous of China. Acta Paleont. Pol. 48: 235259.

Leanza, H.A., S. Apesteguía, F.E. Novas \& M.S. De La Fuente. 2004. Cretaceous terrestrial beds in the Neuquén Basin (Argentina) and their tetrapod assemblages. Cret. Res. 25: 61-87.

Long, R.A. \& S.P. Welles. \&. 1974. The tarsus of theropod dinosaurs. An. S. Afr. Mus., 64: 191-218.

Madsen, J.H. 1976. Allosaurus fragilis: A revised osteology. Utah Geol. Min. Surv. Bull. 109: 1-163.

Makovicky, P.J., S. Apesteguía \& F.L. Agnolín. 2005. The earliest dromaeosaurid theropod from South America. Nature 437: 1007-1011.

Martínez, R.D. \& F.E. Novas. 2006. Aniksosaurus darwini gen. et sp. nov. a new coelurosaurian theropod from the Early Late Cretaceous of Central Patagonia, Argentina. Rev. Mus. Arg. Cienc. Nat. 8: 243-259.

Naish, D., D.M. Martill \& E. Frey. 2004. Ecology, systematics and biogeographical relationships of dinosaurs, including a new theropod, from the Santana Formation (?Albian, Early Cretaceous) of Brazil. Hist. Biol. 2004: 1-14.

Novas, F.E. 1996. Dinosaur monophyly. J. Vert. Paleont. 16: 723-741.

Novas, F.E. 1998. Megaraptor namunhuaiquii gen. et. sp. nov., a large-clawed, Late Cretaceous Theropod from Argentina. J. Vert. Paleont. 18: 4-9.

Novas, F.E. 2009. The Age of Dinosaurs in South America. USA. Indiana University Press, Bloomington, Indiana, $450 \mathrm{pp}$.

Novas, F.E., L.C. Borges Ribeiro \& I.S. Carvalho. 2005. Maniraptoran theropod ungual from the Marilia Formation (Upper Cretaceous), Brazil. Rev. Mus. Arg. Cienc. Nat. 7: 31-36.

Novas, F.E, M.D. Ezcurra \& A. Lecuona. 2008. Orkoraptor burkei nov. gen. et sp., a large coelurosaurian theropod from the Maastrichtian Pari Aike Formation, Southern Patagonia, Argentina. Cretaceous Research 29(2008): 468-480.

Novas, F.E., D. Pol, J.I. Canale, J.D. Porfiri \& J.O. Calvo. 2009. A bizarre Cretaceous theropod dinosaur from Patagonia and the evolution of Gondwanan dromaeosaurids. Proc. Roy. Soc. B, 126: 1101-1107.

Novas, F.E. \& P.F. Puerta. 1997. New evidence concerning avian origins from the Late Cretaceous of Patagonia. Nature, 387: 390-392.
Osmólska, H., E. Roniewicz \& R. Barsbold. 1972, A new dinosaur, Gallimimus bullatus n. gen., n. sp. (Ornithomimidae) from the Upper Cretaceous of Mongolia. Palaeontologia Polonica 27: 103-143.

Ostrom, J.H. 1969. Osteology of Deinonychus antirrhopus, an unusual theropod from the Lower Cretaceous of Montana. Bulletin of the Peabody Museum of Natural History 30: 1-165.

Ostrom, J.H. 1978. The osteology of Compsogathus longipes Wagner. Zitteliana 4: 73-118.

Rauhut, O.W.M. 2003. The interrelationships and evolution of basal theropod dinosaurs. Spec. Pap. Palaeont. 69: 1-215.

Rauhut, O.W.M. 2005. Postcranial remains of "coelurosaurs" (Dinosauria, Theropoda) from the Late Jurassic of Tanzania. Geol. Mag. 142: 97-107.

Rauhut, O.W.M. \& X Xu. 2005. The small theropod dinosaurs Tugulusaurus and Phaedrolosaurus from the Early Cretaceous of Xinjiang, China. J. Vert. Paleont. 25: 107-118.

Rauhut, O.W.M., A.C. Milner \& S. Moore-Fay. 2009. Cranial osteology and phylogenetic position of the theropod dinosaur Proceratosaurus bradleyi (Woodward, 1910) from the Middle Jurassic of Portugal. Zoological Journal of the Linnean Society, 2009: 1-41.

Roach, B. \& D. Brinkman. 2007. A reevaluation of cooperative pack hunting and gregariousness in Deinonychus antirrhopus and other nonavian theropod dinosaurs. Bulletin of the Peabody Museum of Natural History, 48(1):103-138.

Rowe, T. 1989. A new species of the theropod dinosaur Syntarsus from the Early Jurassic Kayenta Formation of Arizona. J. Vert. Paleontol., 9: 125136.

Sampson, S.D. \& L.M. Witmer. 2007. Craniofacial anatomy of Majungasaurus crenatissimus (Theropoda: Abelisauridae) from the Late Cretaceous of Madagascar. Mem. Soc. Vert. Paleont, 8: 32-102.

Sereno, P.C., R.N. Martinez, J.A. Wilson, D.J. Varricchio, O.A. Alcober \& H.C.E. Larsson. 2008. Evidence for Avian Intrathoracic Air Sacs in a New Predatory Dinosaur from Argentina. PLoS ONE, 3: e3303.

Seebacher, F. 2001. A new method to calculate allometric length-mass relationships of dinosaurs. J. Vert. Paleont. 21: 51-60.

Turner, A.H., D. Pol, J.A. Clarke, G.M. Erickson \& M. Norell. 2007. A basal dromaeosaurid and size evolution preceding avian flight. Science 317: 13781381.

Turner, A.H, D. Pol \& M. Norell. 2011. Anatomy of Mahakala omnogovae (Theropoda: Dromaeosauridae), Tögrögiin Shiree, Mongolia. American Museum Novitates 3722: 1-66.

Varricchio, D.J. 1995. Taphonomy of Jack's Birthday Site, a diverse dinosaur bonebed from the Upper Cretaceous Two Medicine Formation of Montana. Palaeogeogr., Palaeocl., Palaeoecol. 114: 297-323.

Varricchio, D.J., P.C. Sereno, Z.X. Xijin, T. Lin, J.A. Wilson \& G.H. Lyon. 2008. Mud-trapped herd captures evidence of distinctive dinosaur sociality. Acta Paleont. Pol. 53: 567-578. 
Welles, S.P. 1954. New Jurassic dinosaur from the Kayenta formation of Arizona. Bulletin of the Geological Society of America 65: 591-598.

Xu, X., J.M. Clark, C.A. Forster, M.A. Norell, G.M. Erickson, D.A. Eberth, A.C. JI \& Q. Zhao. 2006. A basal tyrannosauroid dinosaur from the Late Jurassic of China. Nature, 439: 715-718.

Xu, X., J.M. Clark, J. Mo, J. Choiniere, C.A. Forster, G.M. Erickson, D.W.E. Hone, C. Sullivan, D.A. Eberth, S. Nesbitt, Q. Zhao, R. Hernandez, C. Jia, F. Han \& Y. Guo. 2009a. A Jurassic ceratosaur from China helps clarify avian digital homologies.
Nature 459: 940-944.

Xu, X., Q. Zhao, M. Norell, C. Sullivan, D. Hone, G. Erickson, X. Wang, F. Han \& Y. Guo. 2009b. A new feathered maniraptoran dinosaur fossil that fills a morphological gap in avian origin. Chinese Science Bulletin, 54: 430-435.

Zheng, X., X. Xu, H. You, Q. Zhao \& Z. Dong, Z. 2009. A short-armed dromaeosaurid from the Jehol Group of China with implications for early dromaeosaurid evolution. Proc. Royal Soc. London B, published online before print August 19, 2009. DOI 10.1098/ rspb.2009.1178.

Recibido: 19-III-2012

Aceptado: 29-V-2012

\section{Appendix 1}

List of characters that have been added to the original data matrix of Zheng et al. (2009). The enumeration given below continues that of Zheng et al. (2009):

361) Rostral process of quadratojugal: equal or longer (0); shorter (1) than the dorsal process of the quadratojugal.

362) Pubis distal end: transversely broad, expanded from the transverse width of the shaft (0); transversely flattened (1). (Benson et al., 2010)

363) Facet for the reception of the ascending process of the astragalus in the distal end of the tibia: medially bounded by a sharp step (0); bounded medially by a very slight edge or without well-defined borders (1).

\section{Appendix 2}

Scorings of the operational taxonomic units included in the present phylogenetic analysis:

Dilophosaurus wetherilli

?110000010010000001000000000000001?001001??????010000000000??????000100000?000000000001010100100001310001000010?00010000000

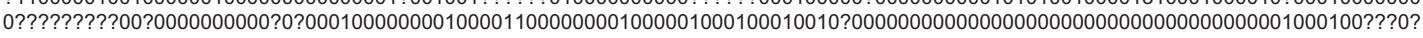
0000??0000010000000110??02?1010011000001000?000??0000010000000000001001000000000?00?00000000000000000?0100000??00000000 Elaphrosaurus

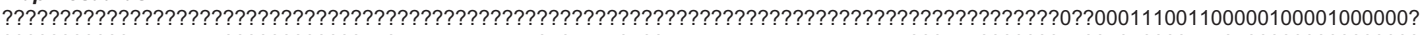

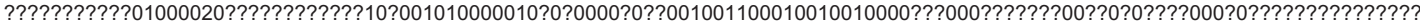
????????????????10011???????00?????????????????????????000011100100?0???0000?????00?000000?00??????????0????100???1

Piatnitzkysaurus

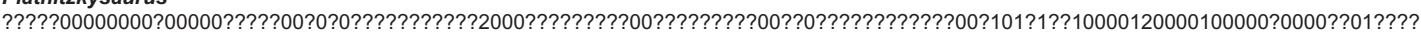

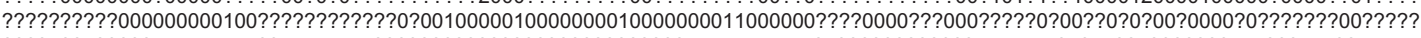
????0??0?????000000101??00000100?????????????????????????+00010000100?0???????????0000002?0?00??0???????000???000??00

Allosaurus

$? 11000 ? 000000000001000100010000000010110020102000000000000010000000000000010000000000101010010000000100100000000001 ? 010000$ $000011 ? 0000000000001000101000101000000100000100000000100000000110000001000000000000000000000000000000000000000000000000000$ 00000000000100000000000000000000000000000000000100000000001000000000000000000000000000000000000000000000000000000000000 Sinraptor

?110000000000?00001000100010000000110110020102000000000000010000000000000010000000000101010010000000100100000000001?010000 000011?0000?0??0????????????01010000001000001000000001000000001100000010000000000000?00??0000000000000??000000000000000000 0000000000010000000000000???????????????????????????????1000000000010000000000????0000000000??000?0010?000000000000000

Mapusaurus

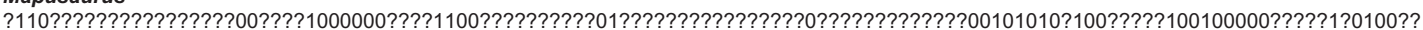
?0011?????001?00????????????????0000010000010????000????00000110000001000000??00??0?????1,00?0???????000000?????0?0000000 0???0?0?000??000???000??000?0???????????????????????????0?0000?00000?00???????????00?0?0??0?00??0???????0???????1???0 Aniksosaurus

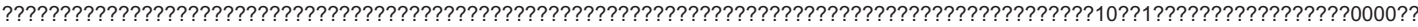

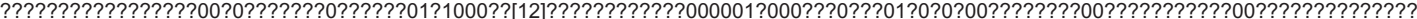
???????????????????????????????????????????????????0?0???????????1,??1,00???????????0?00???,00?00?????????0?????00???0

Bicentenaria

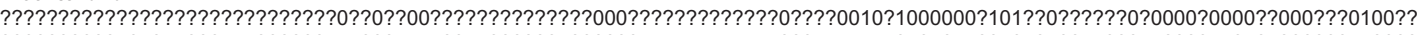

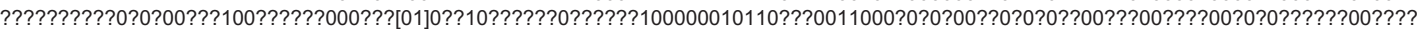

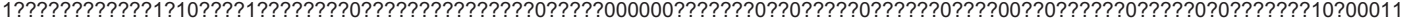

Tugulusaurus

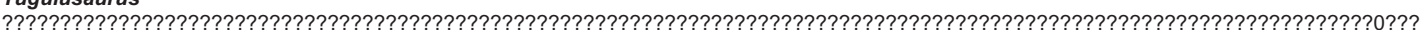

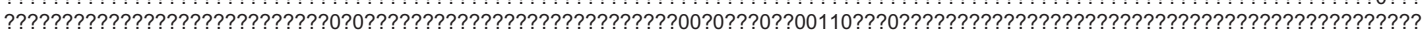


???????????????????????????????????0????????????00??0?????????1,0???????????????????????????????????0?????????????0

Zuolong

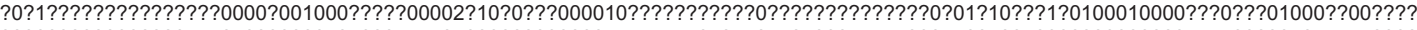

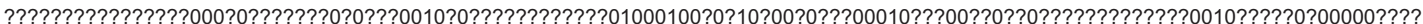

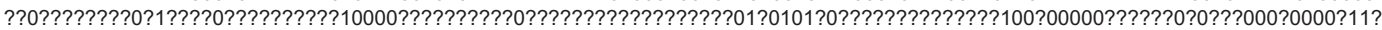
Dilong paradoxus

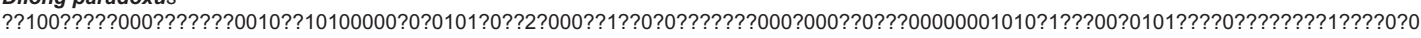

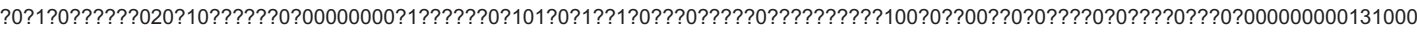
0000000?0???110?0001100?0001011?1??00?10000100010000000001?0001010?10110000000000010???0?01?00??0?0?0000100?0???00001??

Eotyrannus lengi

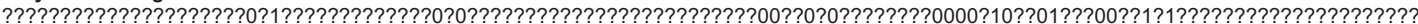

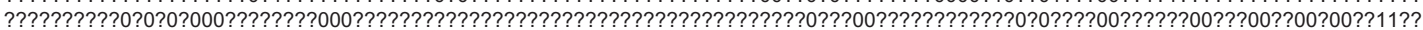

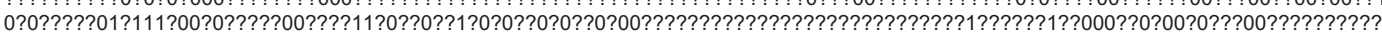
Tyrannosaurus rex

?10000?00?00000002100001101010000000001012010211000010010001?000000000000010010000000101011010000000100101000000101?000000 00??1????0000000010100??0?010001001000100000101101101000000000100001000100000200000001000000000000001000100000000000101100 $0000000001011000000000000101000000 ? 001110001000 ? 0 ? 00 ? 0 ? ? ? ? 01001001010110 ? 0000000 ? ? ? 000100000000000010000100000000100111$

Gorgosaurus libratus

?10000?00?000?0???10000110111000000001101201?21100?010010001????00000000001001000000010101101000000??00101000000101?000000 00001????00000000101000001010001001000100000101100101000000000100001000100000200000001000000000000?01000100000000000101100 $00000000010110000000000001110000000 ? 01100101000 ? 0 ? 000000 ? ? 0100100101011000000000 ? ? ? 000100010000000010000100000000100111$

Tanycolagreus topwilsoni

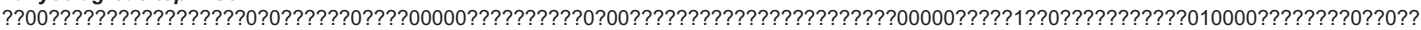

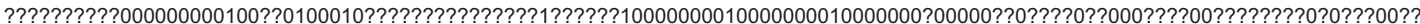
0?0?????????1??????110??0010011110000111000100010001000001?????010010110000000000011??1?0?1??00000?00??0?000?????0??111

Coelurus fragilis

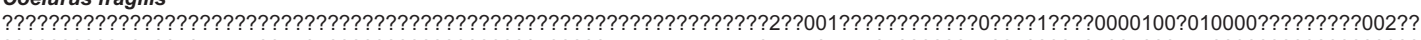

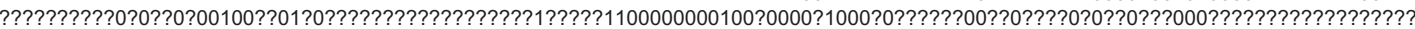

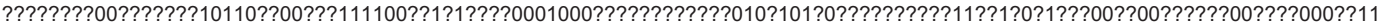

Ornitholestes hermanni

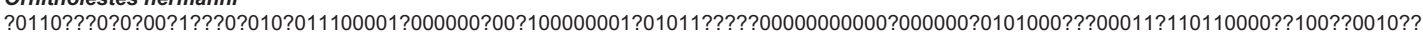

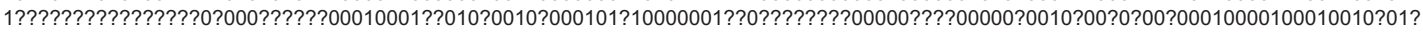
?1000?100?000?00001110???????11010?0???????0?????000100??010010?0?101?0???????0????000000100000??0??1101??0000000001?1

Compsognathus longipes

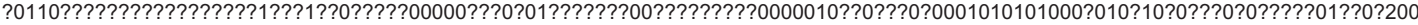

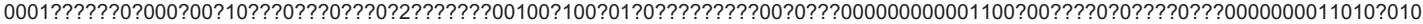
0100001?00??0?0?0001100?0001010010???????????????0?0?10??0100101??1011000000000??0?00?00010?000000??1110?000??00000?11 Huaxiagnathus orientalis

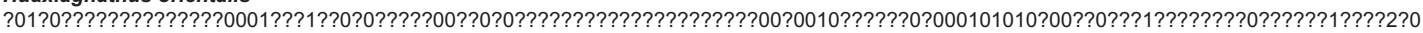
$00010 ? ? ? ? 000000000 ? 10 ? ? 1010000000020 ? 0 ? ? 1000100 ? 000001 ? 0 ? ? 0 ? ? ? 0 ? ? 0 ? ? 0 ? 01000000000 ? 011 ? ? 000 ? ? ? ? 00 ? 0 ? ? ? 0 ? ? ? 0000000011010 ? 010$ 0100001?0???1?0?00011?0?0000010000000?00000100010?0000000?0100101??10110000000?0001000?00010000000000?10000?0????000?11

Sinosauropteryx prima

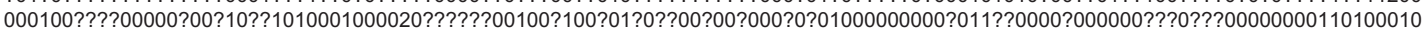
$0100001 ? 0 ? ? ? 0 ? 0 ? 0001101 ? 0001000000000 ? 0000010001000000100001001010 ? 1 ? 110000000000 ? 10000 ? ? 010000000001110000 ? 0 ? ? ? 0000 ? 11$ Juravenator

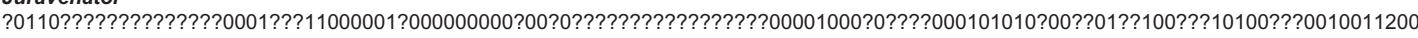

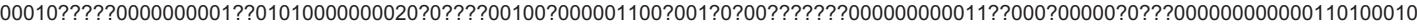
0100001???0000000001101?0001000000000?000001000100000010000100101011011000000000001000000010000000001110000?0??00000???

Mirischia

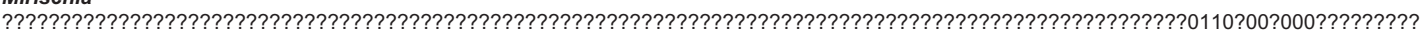

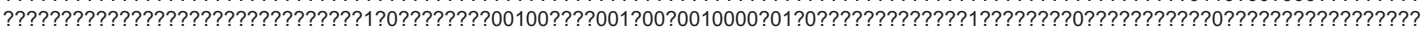
??????????????????110???????????????????????????????????10010???????????????????000?????0???????????????????????1?

Nqwebasaurus

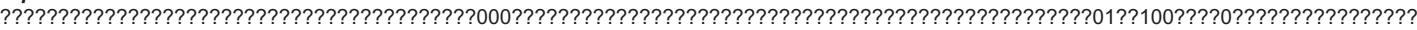

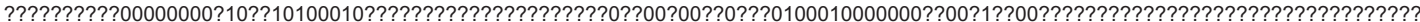
????0???????????001????00010?00?000000000010?01000???1000?????010?001?0????????,0?0???????????????01??1?000????000???1

Santanaraptor

??????????????????????????????????????????????????????????????????????????????????????????????????????

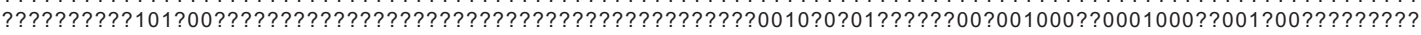

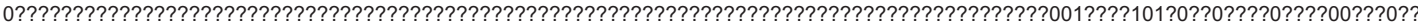
?0??00?????????0??????????1

Deinocheirus mirificus

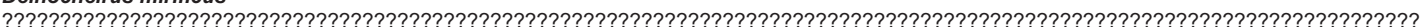

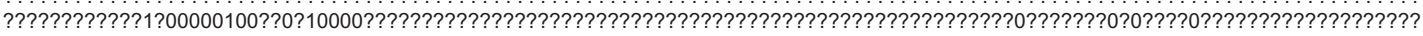
????????????????????????0?0??10?0??110000010000000000001?????????????????????1100??????????00???11??1?0???????????? Harpymimus okladnikovi

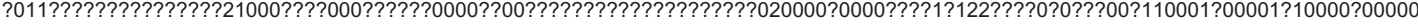

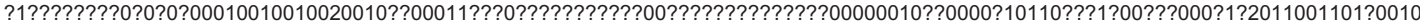
0?00101?00?0???0000110??00?0??10?00001000001000000000010020????0????01?0???00000010000?00?1?0000?0000??110?00?0?0000??? Pelecanimimus polyodon

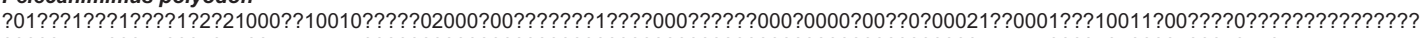

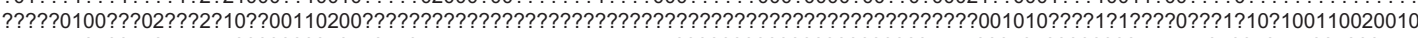
0100101?0??00?010001????????0?10?00?1100011100001000012002??????????????????????1100???0?0????????01111110??0?000??0??? Shenzhousaurus orientalis

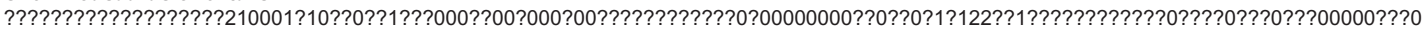

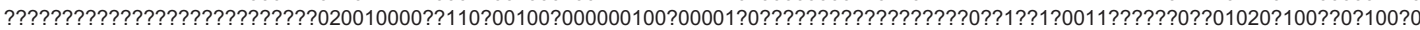

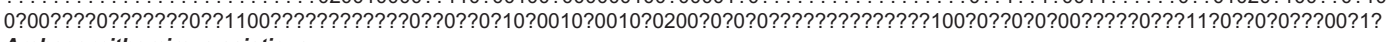
Archaeornithomimus asiaticus

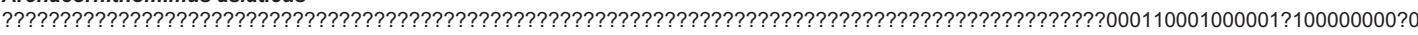

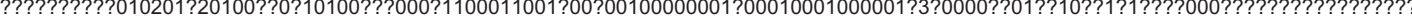
?????????????????1110??00??0?10?0??110?0001000?1??001200??00010100?11?0?????????0000?000100?00???11??1?001????010??11

Garudimimus brevipes 
?0110????01101????021001101001000??002000000000010?1??0?0001??1??0000000000020001?1?3???????01100???000??0?001??

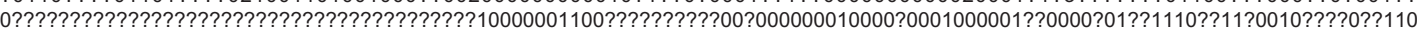
0110120010010010100000?????11110??????????????????????????????????0????010110110010???00?????000?1000??000???1????00000 0000111

Anserimimus planinychus

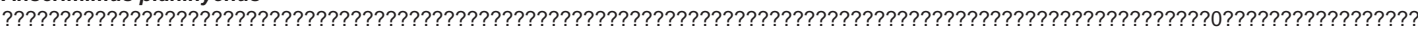

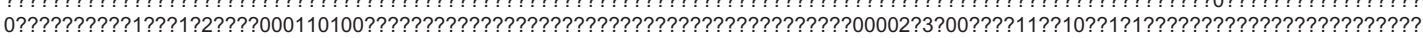

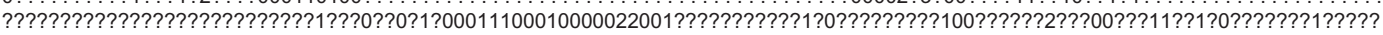

Ornithomimus edmontonicus

?01110?110?101?101021001101?0100211000000000000000010000000??????00000000010??001?1?3??????001?0011000010000010100000000?0 01001?????011201020100000?101001000000110001100100000010000000110001000100000203?0000111111101?11100?000??0??1101110120010 0100101?0?0??????1?1100?0011011010?01?0001110001100002200200001010?111?0???10000110000?000200000?0011?11100??0000100111 Struthiomimus altus

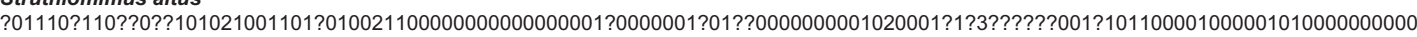
01001?????0112010201000001101001000000110001100100000000000000110001000100000203?0000111111101?111001000??0??1100110120010 010010100?10?????1111000001001101000110000110000100001100200001010?11110???10000110000?000200000?0011?1110010?000100111

\section{Gallimimus bullatus}

?01110?11011010101021001101?01002110000000000000000100000001?01010000000001020001?1?3?????0011001100001000001?10000000000 0100??????0112010201000?01101001000000110001100100000010000000110001000100000203?0000011111101?1110010000?0??1100110120010 010010100000?????111100?00?0011010001100000100001000011002000010101111?0???100001100000000200000?0011?11100100000100111 Falcarius utahensis

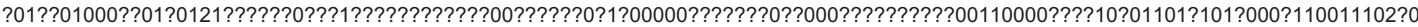
11?????????00?100011011?0000000100?11001010220001210101000000010001001010000000?00000??0???10?00?0?01111111111????????????? ???????00?????0001?11???0?????11?01?0111000100010000000100021?101????0?0?0?00?000010???000000000000?0??0?0??????00????

Beipiaosaurus inexpectus

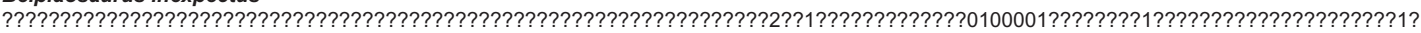

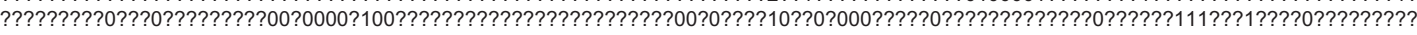

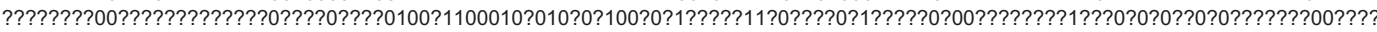

Alxasaurus elesitaiensis

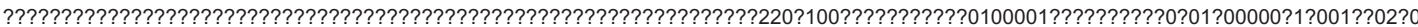

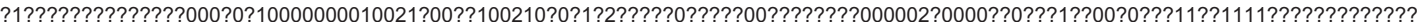
????????00???0?011111??????0?100101?011??00?1??????110012?1?001???00???????00000??0?11?000?010001?0????000????????0???? Nothronychus mckinleyi

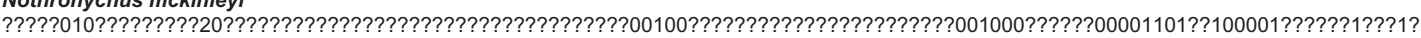

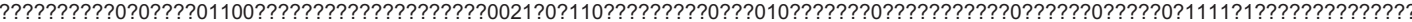

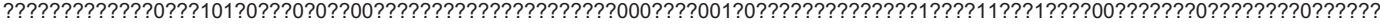

Erliansaurus bellamanus

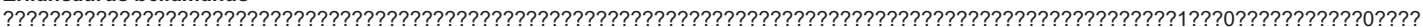

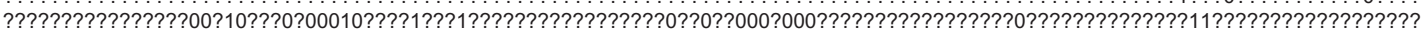

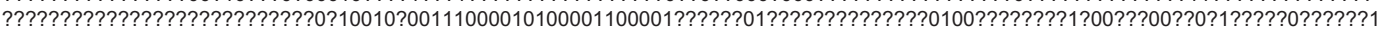

Nanshiungosaurus brevispinus

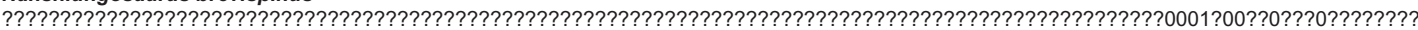

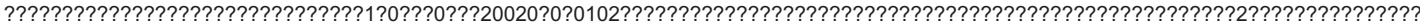
????????????????1?010??????????????????????????????????100111????????????????????0???0??1???1,?????????????0?????? Neimongosaurus yangi

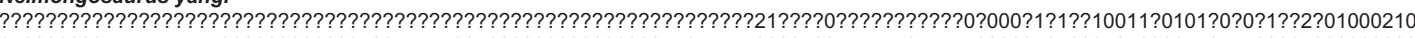

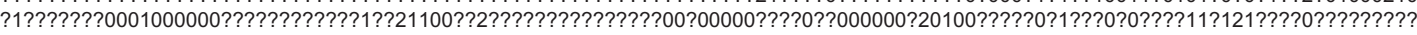
????????0??????0111110000???010?1??????????????????????????????010000?00??0000????????0??001110100?????0?01????000????

Segnosaurus galbiensis

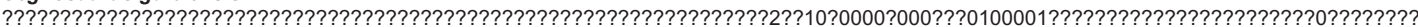

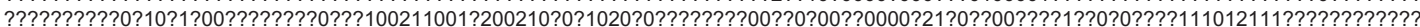

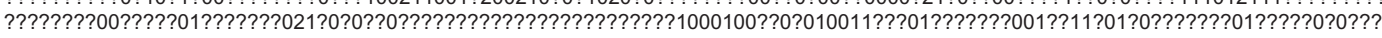
Erlikosaurus andrewsi

?0110??02?1?1?0???010011100??10001?100000100011000?0??00100??11112200100000020001200100001???????????????????????????????

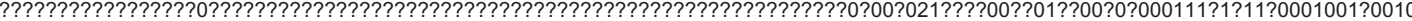
0100001000000001?????????????0???????????????????????????????????0?0?001100001??????????0?+111100???1????0100???01??

Therizinosaurus cheloniformis

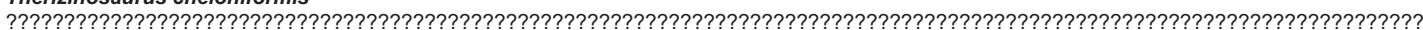

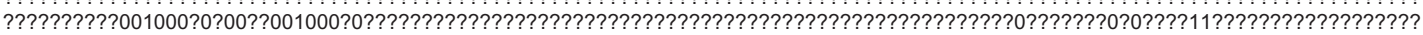

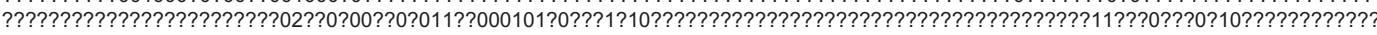

Patagonykus puertai

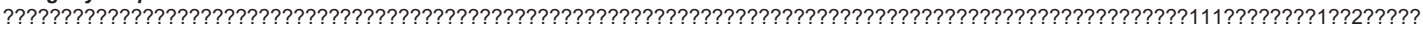

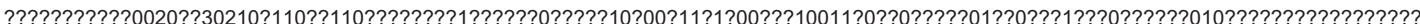

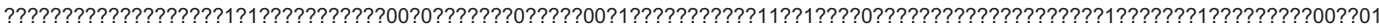

Mononykus olecranus

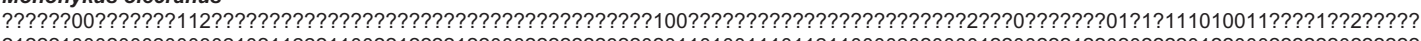
?1???1000?000200030210?1122?1100??1????1??000??????3??0?0110100111011211000020?00001??00???1??0?0????01??000?????0??????

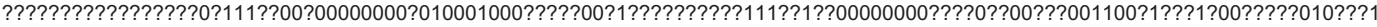

\section{Shuvuuia deserti}

?011010000000?112010000?00??00?111??000010000101010010010???1?110001000000021000?021??000??01111110111101?0??1?201??201200 $0100 ? 1000 ? 00020 ? 03021 ? ? 1122011000 ? 1 ? 1011 ? 2000 ? 00021032 ? 0 ? ? 1101001110112110000201000 ? 11000001100000010001 ? 1 ? ? 0 ? 100110 ? ? 0010$ 010010110?00??0?0???????001?00000??0???001?000??0?000110???0????1??111?000?0010011000?00002?001100012111101?0?0?0100?11 Protarchaeopteryx robusta

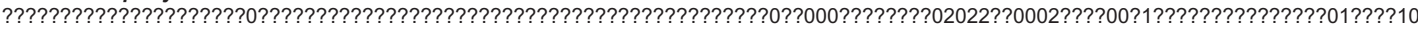

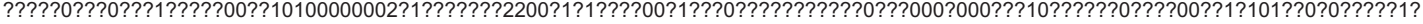
0?0???????????:010?11?0000?001111000??010??10?01000100000000001011?1?1?000000??00000??0000100?000000011010?1???????0???

Elmisaurus rarus

??????????????????????????????????????????????????????????????????????????????????????????????????????????????????????

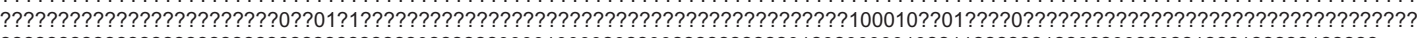

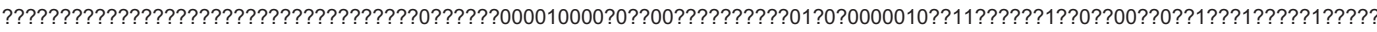

Caenagnathus collinsi

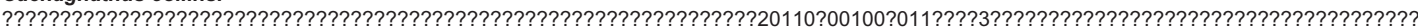
????????????????????????????????????????????????????????????????????????????????00??0??????0????0??????????????????? 


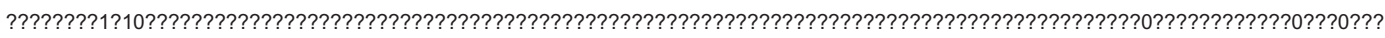
Rinchenia mongoliensis

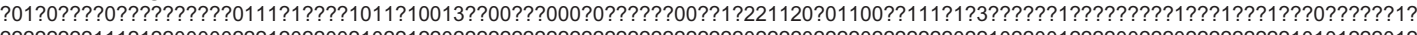

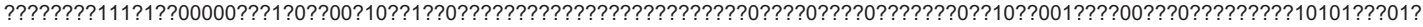
01110?010?10?????????????????1???????????????????????????0??????1?????????????????????????0?????1???1?????11100?11??? Citipati osmolskae

?011001001001??2210001111110001011?10013210001100000110011000110221120?0110010111?1?3??????1011001100101111001??20???00210 0111?011111?010000100?11000001110021100?110220?0??1010010?1101000000100?0000010000000100100110?000000000??0???010101101010 01110101001??????10????010?001011010010100000000000000100??????1??101?00000001011001000001??00000100?10?01?1110?0?10??

Ingenia yanshini

?01?0???????????????11111100010?1?1??132??0?1???0?0??0011?????1221120?01100?01111,1?3??????????0??1??1???1???2???01????210 $0 ? ? ? 0011111111 ? 000000 ? ? 10000010100211 ? ? 11 ? 022000011010 ? 110110100000 ? 100100000000000 ? 1100 ? 0 ? 11 ? ? 000 ? 0 ? 0000 ? 0 ? ? 101010110 ? 01 ?$ 01110?010?10??????????0010?001011010010100000010000000110000001011?101?00?????00100010000000000000101?10101101100011??? Khaan mckennai

?0110?????????????00111?110?01011?1001321000110?000??00110??????21120?01?00?0111?????????10110??1??1011110?????1??00210 ?111001??111110000?00?1100000111002110?1110220001?101??1??110100?0??10010000000000000100100110?000???000??0??1010101101010 011101010?10?????001110010?001011010010100000000000000110000001011?1011000000000100010000000000000100?10101?0?1010110?? Heyuannia huangi

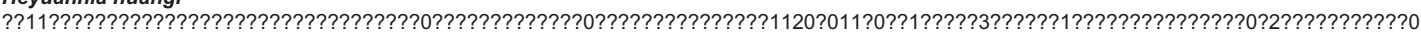

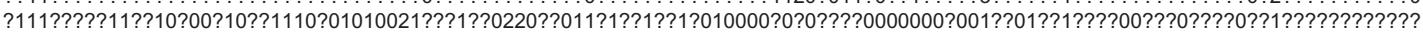
????????0?1??????00?110010?00?01?0100001000001?0?00?01???00000011?1?1?0?0001000???010?0?00?0000001?1??0?01?0????01???? Sinovenator changii

?0???1002?000011120000101?11100???1??????000011???011?10100??????000?001??????0000021??01?????11?111000110100001000110????

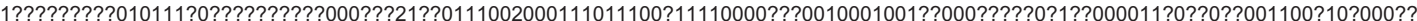
010?1?1100??0?00001111??00100?????????????0?????000000???2011011?101?1???0011??0??1000102?00??000??1?0??110???00???1?

Mei long

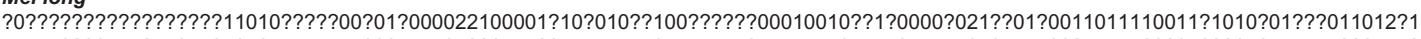
$11011 ? ? ?, 101 ? 11 ? 10 ? 0 ? 1$ 10000000???2111?1???020??11101110?0111100?0101101?0001?11011?0?0000???00000????0????0?110011???001? 0100101?????????1111??00010011110?0??0?????0?????00000???????:1??1?11100?1?1??000?11??1?21?000000?01?010110???0?00???

Byronosaurus jaffei

?????101???101?1100110101011?00??????20220???????????1?100??????0000001??11????00021??01?0?0???????010110???????0??0

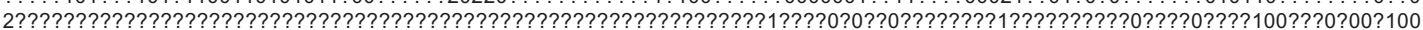
?101100??0100???10?00110????????????????????????????????????????????????????????11,?????????????????0??11,???? 0?????????

Sinornithoides youngi

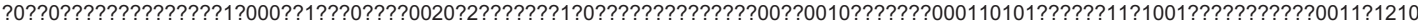

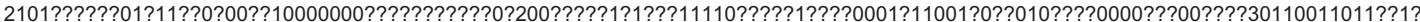
0100??1?000?1?0?011???0?00??01111010010100010000000000000???0???11?1111100011111000010????2100000000001?010110???0?0?111 IGM100 44 unnamed troodontid

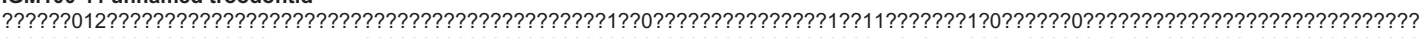

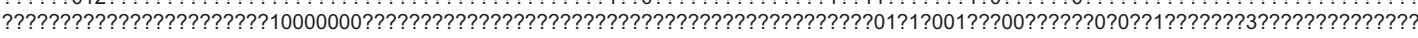

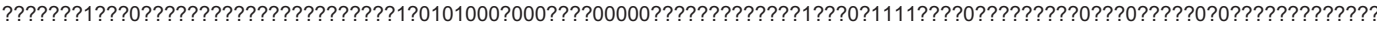

Troodon formosus

???1?1112?1101000001???0?010100??????20220000210?00?1?01100????0?10??001??????????011010100???1111100101101111?1000?1020??

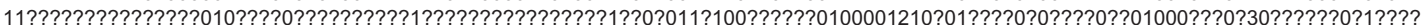

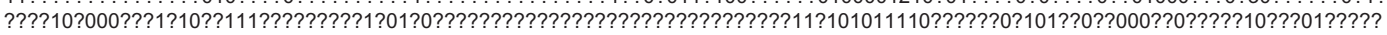
Saurornithoides mongoliensis

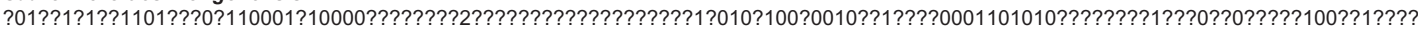

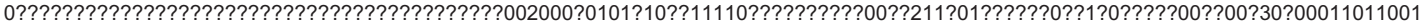

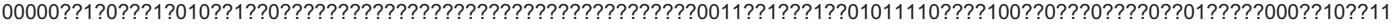

Saurornithoides junior

?01101?12?110100?001?000??100?000????2022000?21??0????11100??????100?001???1????00011010100?????????????????1?1000?102

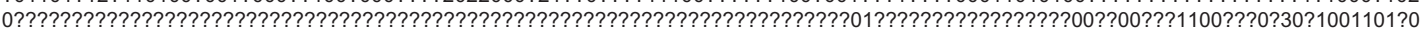
01000001010000?110?0?????0????????????????????????????????????????????11?????????????1????????????0??01?1???0?0??1????? Unenlagia

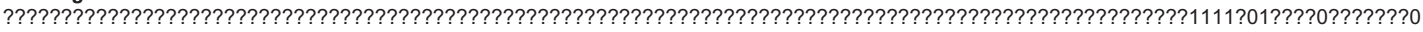

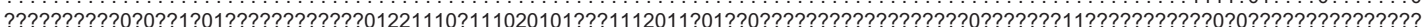

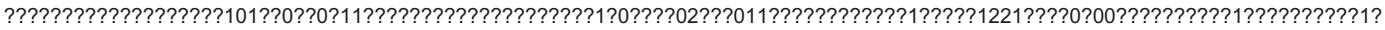

Buitreraptor gonzalezorum

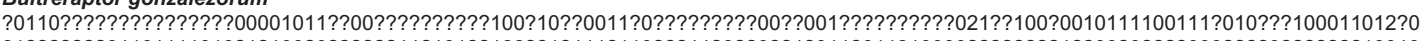

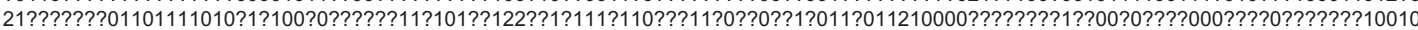
01?0?01?0??????0?0?111?00?10011120???????????????????????0?101?1????1?0???0?2??????12011021??000?0??1??1?1?0??0?000??1

Rahonavis ostromi

???????????????????????????????????????????????????????????????????????????????????????????????01111110?1+11?011012?0

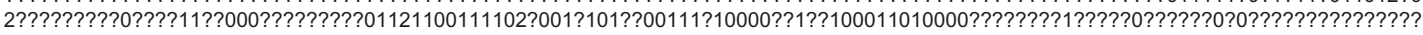

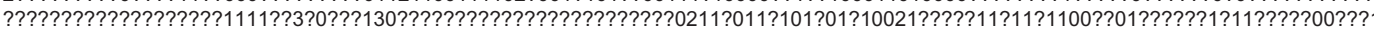

\section{Bambiraptor feinbergi}

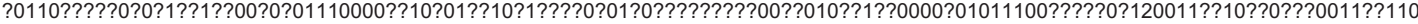
?????0011001011110?001?1010000010?21?001110020001?1021100?1?110000??10010001101?0?000?00?0?1??0000????000?0000000?1013001? ?100101?10?011100011011000?00111201011010001000001011001010201101101?100001001100?001200101100000100001011110???000011? Tianyuraptor ostromi

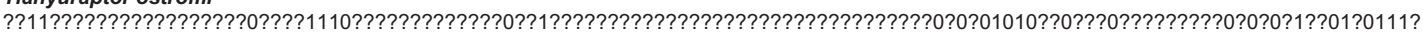

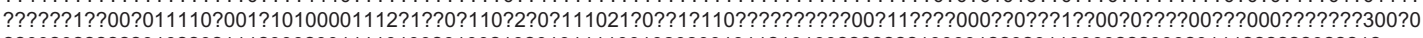
??00?0?????:010??0?111?000?0011110100?0100?10?01011110010202001011?10100???????100001??0?0110000???000?0111??????0???1?

Sinornithosaurus millenii

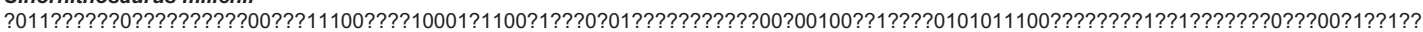
????:0111?01031110?00???0?0000010?211?0??10?2?0?111022?0????1???????1?01000112110?0?000?1001??0000???0??00?0001001101300?0 ?100101?1?00110?0??????00010011121?00101100001000111100001?211111??1?100001201?0000012??112?000001000110101?0????0??011 Microraptor zhaoianus

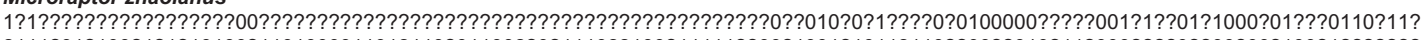
2111?01?100?1?1?10100?1101000011012110?011002?0?111022100?11111??00?1001?10112110??00??010?11?000????0??00?00?100?1??????? ??00??1?1?0???0??0?11110001001112110??0110000100011110010002111110?1?100001201110000020?11210000010001?0101?0???000???1 
NGMC91

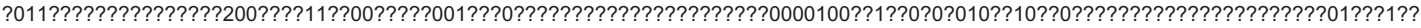

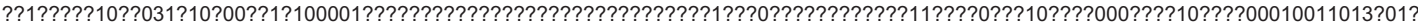
1100??1?1?0?1?0?00?????0?0?001112110??011000?1000110100100??????1??1?1??001201110000??????21?0000100011010??0??????0??? Tsaagan mangas

?011001001000012011200001010100001?100012110110001000??00001?0???00000100?11110001010101000????0??

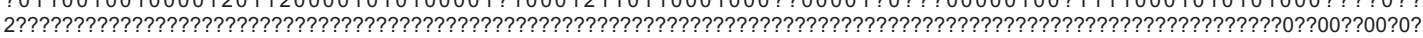
0000???0?0??00010013?0001000001?1???0?0?0?????????????????????????????????????????????????????????????????????????? 0???1?????0???????0??

Adasaurus mongoliensis

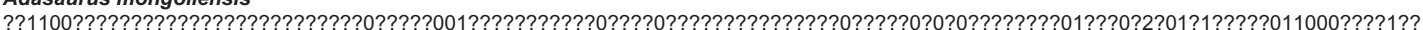

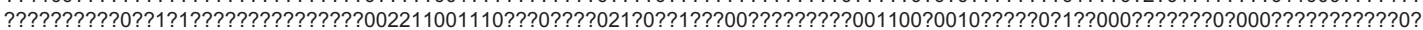

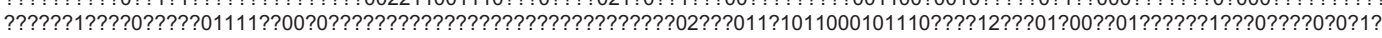
Velociraptor mongoliensis

?0110010010000120112000010111000011100012111?:10001000100001110101000001001111000010101110000110001200111110111110001101110 $2111001110011111101001110000001002211001110020001111211001111000000010010101101001000000 ? 001100000000000000000000100130000$ $100000101001010000110100001001111010010100010000000110010202001011 ? 001100000111000001200101100000100001010110000 ? 000011$ Saurornitholestes langstoni

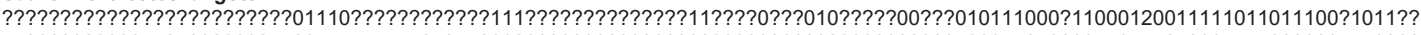

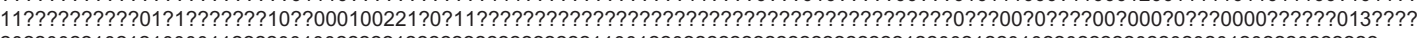

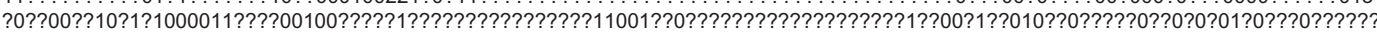

Deinonychus antirrhopus

?0110????1???????11?0000?0111000011100012??????0?1????0?00?11010?000?0100111?1000?010111000?1100012001?111011????00110110? 21?10???1?010111101001110000001002211001110020001110?01001111100000010010001101000000?00?001100000?0?000?0000??00?0013000? 000????000?1?110001001??????0111101001010001000000011001020000101100011000101110000012?00001000001000010101100000000011

Achillobator giganticus

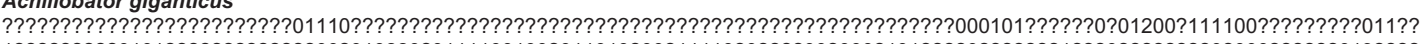

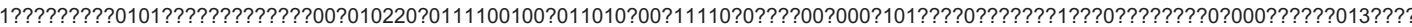
?????????????10??00000??00??0???1???????????0????01?0????0000100100?1??????11??????1000000?0??????????0??1?????0????1?

Dromaeosaurus albertensis

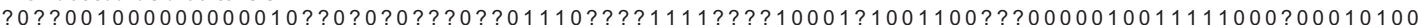

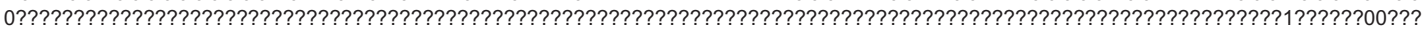
???00?0?0000???0?00?000?00????0??00?0010010100000????????????????????????????????????????????????????0111??????????

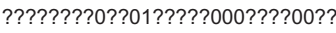

Utahraptor ostrommaysi

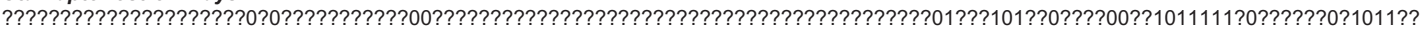

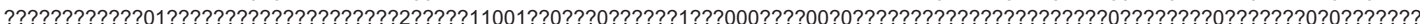
????????????0?????000????????????????????????????????????001,00?????????????????10???0???????????0?????????0??????

Atrociraptor marshalli

? ? ? ? ? ? ? ? ? ? ? ? ? ? ? ? ? ? ? ? ? 11110 ? ? ? ? ? ? ? ? ? ? ? ? ? ? ? ? ? ? ? ? ? ? ? ? ? ? ? ? ? ? ? 0 ? 1 ? ? ?

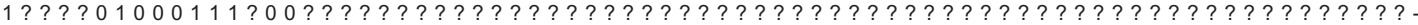

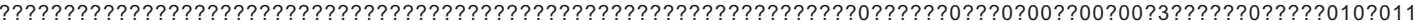
0????????????????????????????????????????????????????????????????????????????????????????????????????

Epidendrosaurus ningchengensis

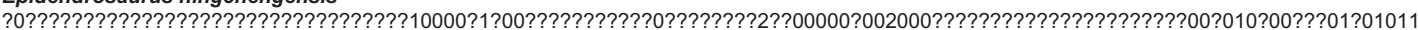

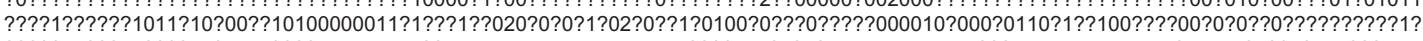
?????01???10????00?1111????002102010??010001000000000000000????011?1?1?0110200001100???00011000000010?11101?0??1?000???

Archaeopteryx lithographica

$101 ? 0010 ? ? 000 ? ? 112011010 ? ? 11100 ? 011 ? 00002100010 ? 0000 ? 0 ? ? 100111 ? 10000001000002 ? 0000020 ? ? 00000 ? 111 ? ? 100 ? 0 ? ? 010 ? 0 ? ? ? 002101211$ $1000 ? ? ? ? ? 001011110000 ? 11000000101121 ? 0001 ? 002000121011101 ? 111100000 ? 10010010 ? 0010 ? 0000001001100000 ? 0 ? 000010200101110100010$ 0100101?0??00?0001?11110?3?0121130110?0100010001000010010202010011?1011011120010000010000121000000000110101?00000000?11 Wellnhoferia grandis

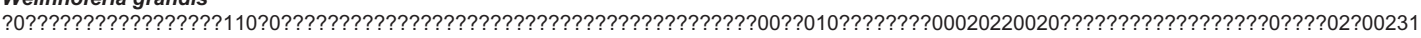

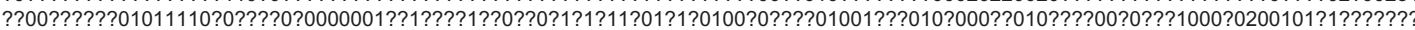
0?00????0???0?0?0??11?1?0310?21130?10?0110010001000010010202???011?1?110111200?000001??001210000000001?0101???????0??1?

Jeholornis prima

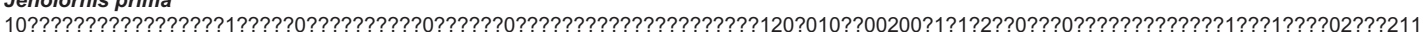

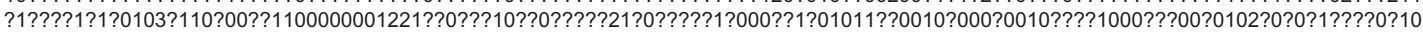
?1???01?01?0????01?1111?031012113011??011000?110011000000002???01??1?1?01112000100101??0?111000000000?10101?0??1??00?11 Sapeornis chaoyangensis

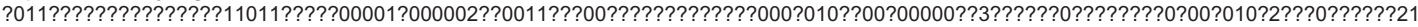

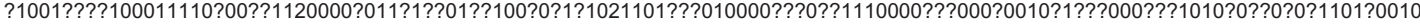
0?0??01?0??0?????1?111?0031012113111?1011100?1110011100?1?02???011?1?110111????1??101?00?01?000000000110?0110??1?00?11?

Confuciusornis sanctus

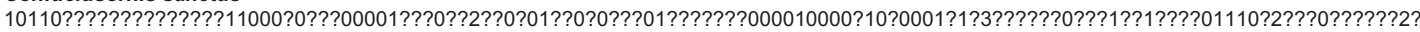
?111?110100013111400011111000010112101????100?0012103210111??10??11?1121111010010?000000100110?000???001??0??0011?????0010 0000?01?0?10?????11111?0001012112111010100000101010110010002???011?1?1101112000101101??0011?000000000?10?01?0??100?2?11

Protopteryx fengningensis

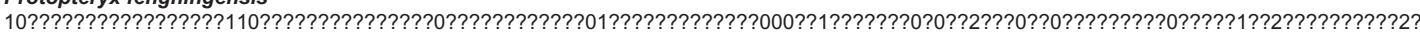

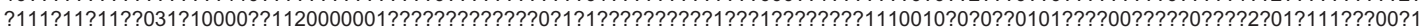
0?00?01?0??????01?????1?3?012113111??011000?110010110001???????11?1?1?0111200?0??10??????1??00000000110?01?0????0???1?

Yanornis martini

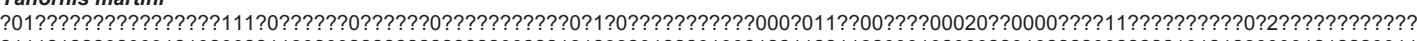
?111?1???0?0031?10?00??1120?00?????????????00???121?32?01???0100?1??11??112?00010?000??010????00?????101?1?200001?1???0011 0?00??1?00?00?0001111??1???012113111??0110?0011?0?1111101??????01??1?1101??20000???0??????1??00000000110?0??0??10?????1 Hagryphus giganteus

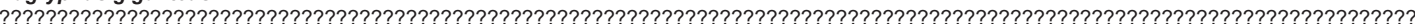

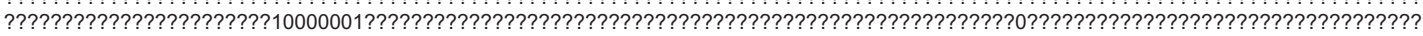

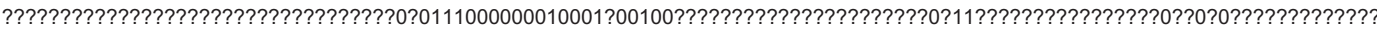

Alvarezsaurus calvol

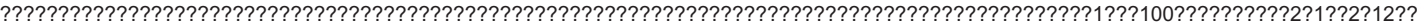

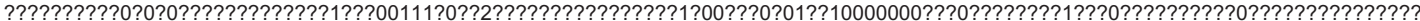

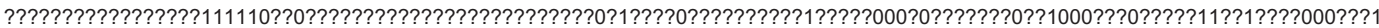


Microvenator celer

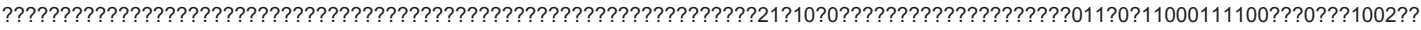

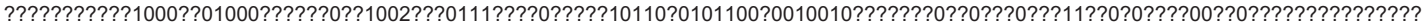

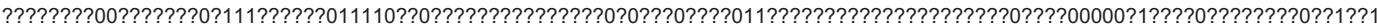
Avimimus portentosus

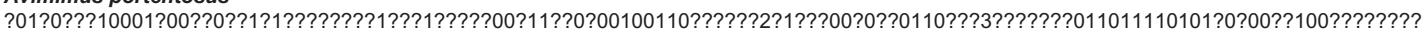

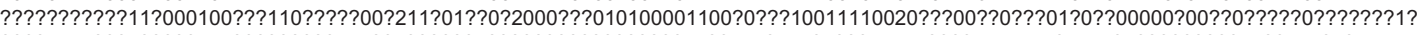
????1011???0?????001?????????111??1??????0?????????????????00??011?101?0???00000????1000002?0000?0????????10??011?0?11

Caudipteryx

00110??????????????0?110?010000011?00013210001?00?00????????????21010?00?????10031?3?????00????0?100????????0???01????210 ?111000??001010001?00??1000000010020???11?02200?111?10?10?11?01??0????01000002000000000010?110?000???0?00?0??1000100100011 0100111?0010?????001110?10?0001110100?01000000010?0001101?00001011?1011000000000???010000010000000000110101?0??000011?1 Oviraptor philoceratops

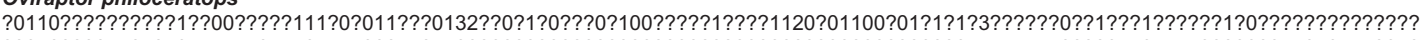

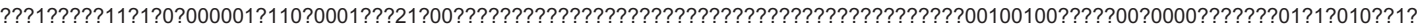
?1?00?010?10?????0?111?010?00?11?01??10100000000000000100??????????????????????1000?????????00??100?10?01?0?10???11??

Conchoraptor gracilis

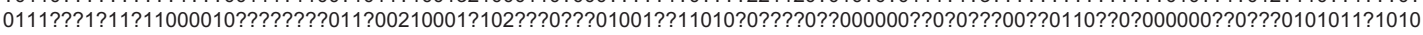

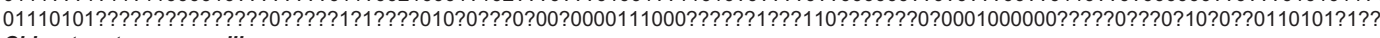

Chirostenotes pergracilis

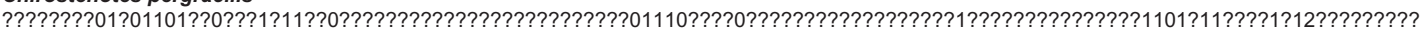

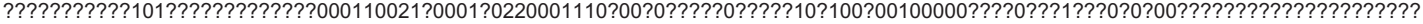
???????1?????????1?1????????0??????00?????000010?0?1001000?001?1??101?000000010001110000?1?000000??0??0???????001???1

Incisivosaurus gauthieri

?0110???1??01?????1000101010001001?0?010??00011000?01010110101111200100001001?1?02022??000

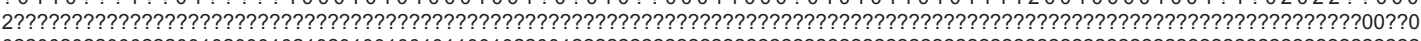
0??00?0??000???0010?00010?10?010010010110010??001??????????????????????????????????????????????????????????????????????? ???????0??11?????0110???0???

IGM100 42 unnamed oviraptorid

?0110??????????????001111110?01011?100132100?11??000???01100?111221120?01100??1111?1?3??????10??0??1??1?1?1???1???01??00?10

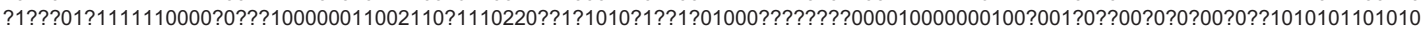
01110101??10?????001010010?001011?100?010001?000000000010000001011?10110???00000110010?00010001000100?10101111101011??? Mahakala

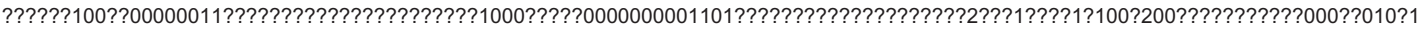

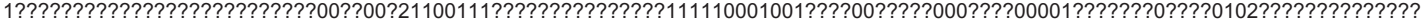

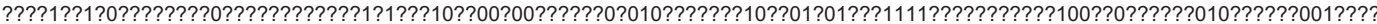

Anchiornis

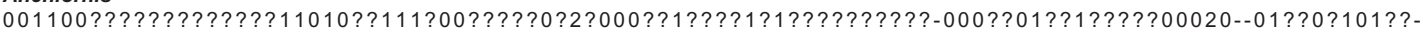
$00 ? 0 ? ? 010 ? 01 ? ? ? 01101210 ? ? 011---011131110000 ? ? 100000010 ? 21 ? 1001102200 ? 1 ? 112112 ? ? ? 1 ? 12000 ? ? 1 ? 01 ? 000121100010 ? 1000 ? 1 ? ? 00 ? 0 ? ?$ ?0????030110?1101000100100?01?0???0-0?011111101?0001112011010100010101001110010102001011?1011000?20?1100001000?121000?0000 0110101?0??0000001?

\section{Appendix 3.}

Table of femoral lengths and respective sources of information employed to analyse body length evolution in non-avian theropods. The femoral length was divided by 100 because TNT 1.1 cannot deal with three digits values. The juvenile individuals are depicted with an asterisk and they were not considered in the analysis. Estimated measurements are depicted between brackets. Abbreviation: Fem, femoral.

\begin{tabular}{|c|c|c|c|c|c|}
\hline Taxa & 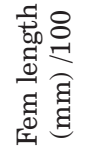 & References & & & \\
\hline \multirow{2}{*}{ Achillobator } & \multirow{2}{*}{5.50} & \multirow{2}{*}{$\begin{array}{l}\text { Turner et al. (2007); } \\
\text { Benson et al. (2011) }\end{array}$} & Atrociraptor & $?$ & - \\
\hline & & & Avimimus & 1.86 & Carrano (2005) \\
\hline Anchiornis & 0.66 & \multirow{2}{*}{$\begin{array}{l}\text { Xu et al. (2009a) } \\
\text { Turner et al. (2007); } \\
\text { Benson et al. (2011) }\end{array}$} & \multirow{2}{*}{ Bambiraptor } & \multirow{2}{*}{1.19} & \multirow{3}{*}{$\begin{array}{l}\text { Burnham et al. } \\
\text { (2000) } \\
\text { Xu et al. (1999); Xu et } \\
\text { al. (2009b) }\end{array}$} \\
\hline Adasaurus & 2.73 & & & & \\
\hline Allosaurus & 10.01 & \multirow{2}{*}{ Carrano (2005) } & Beipiaosaurus & 2.65 & \\
\hline Alvarezsaurus & {$[0.70]$} & & \multirow{2}{*}{$\begin{array}{l}\text { Bicentenaria } \\
\text { Buitreraptor }\end{array}$} & [3.10] & \multirow{2}{*}{$\begin{array}{l}\text { MPCN-PV } 0056 \\
\text { Makovicky et al. } \\
(2005)\end{array}$} \\
\hline Alxasaurus & 5.55 & $\begin{array}{l}\text { Russel \& Dong } \\
\text { (1993a) }\end{array}$ & & 1.45 & \\
\hline \multirow{2}{*}{ Aniksosaurus } & \multirow{2}{*}{2.47} & \multirow{2}{*}{$\begin{array}{l}\text { Martínez \& Novas } \\
\text { (2006) }\end{array}$} & Byronosaurus & $?$ & - \\
\hline & & & Caenagnathus & $?$ & - \\
\hline Anserimimus & 4.33 & Carrano (2005) & Caudinteryr & $1.45-$ & Zhou \& Wang (2000); \\
\hline Archaeopteryx & 0.61 & Elzanowski (2001) & сашанрьетух & 1.52 & Zhou et al. (2000) \\
\hline Archaeornithomimus & 4.02 & Carrano (2005) & Chirostenotes & $?$ & - \\
\hline
\end{tabular}




\begin{tabular}{|c|c|c|c|c|c|}
\hline Citipati & {$[3.50]$} & Benson et al. (2011) & Neimongosaurus & 3.66 & Zhang et al. (2001) \\
\hline Coelurus & 2.10 & $\begin{array}{l}\text { Carpenter et al. } \\
(2005 \mathrm{a})\end{array}$ & NGMC91 & $?$ & - \\
\hline Compsognathus & 0.67 & Ostrom (1978) & Nothronychus & 6.96 & Zanno et al. (2009) \\
\hline Conchoraptor & $?$ & - & Nqwebasaurus & {$[1.18]$} & \multirow{3}{*}{$\begin{array}{l}\text { de Klerk et al. }(2000) \\
\text { Carpenter } \text { et al. } \\
\text { (2005a) } \\
\text { Benson et al. }(2011)\end{array}$} \\
\hline \multirow{2}{*}{ Confuciusornis } & \multirow{2}{*}{$\begin{array}{c}0.42- \\
0.47\end{array}$} & \multirow{2}{*}{$\begin{array}{l}\text { Chiappe et al. (1999); } \\
\text { Zhou \& Zhang (2002) }\end{array}$} & Ornitholestes & 2.15 & \\
\hline & & & Ornithomimus & 6.32 & \\
\hline Deinocheirus & $?$ & 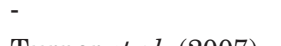 & Oviraptor & 2.62 & Carrano (2005) \\
\hline Deinonychus & 4.40 & $\begin{array}{l}\text { Turner et al. (2007); } \\
\text { Benson et al. (2011) }\end{array}$ & Patagonykus & {$[2.85]$} & Benson et al. (2011) \\
\hline Dilong & $1.81^{*}$ & Benson et al. (2011) & Pelecanimimus & $?$ & - \\
\hline Dilophosaurus & 6.10 & Benson et al. (2011) & Piatnitzkysaurus & 5.70 & Benson et al. (2011) \\
\hline Dromaeosaurus & $?$ & - & Protarchaeopteryx & 1.22 & Ji et al. (1998) \\
\hline Elaphrosaurus & 5.29 & Carrano (2005) & Protopteryx & $?$ & - \\
\hline Elmisaurus & $?$ & - & Rahonavis & 0.88 & Forster et al. (1998) \\
\hline Epidendrosaurus & 0.16 & Zhang et al. (2008) & Rinchenia & {$[2.17]$} & Benson et al. (2011) \\
\hline \multirow{2}{*}{ Erliansaurus } & \multirow{2}{*}{4.12} & \multirow{2}{*}{$\begin{array}{l}\text { Xu et al. (2002); } \\
\text { Benson et al. (2011) }\end{array}$} & Santanaraptor & 1.89 & MN 4802-V \\
\hline & & & Sapeornis & 0.80 & Zhou \& Zhang (2002) \\
\hline Erlikosaurus & $?$ & - & \multirow{2}{*}{ Saurornithoides } & \multirow{2}{*}{2.00} & Turner et al. (2007); \\
\hline Falcarius & 3.40 & $\begin{array}{l}\text { Zanno (2U10); } \\
\text { Benson et al. (2011) }\end{array}$ & & & $\begin{array}{l}\text { Benson et al. (2011) } \\
\text { Turner et al. (2007). }\end{array}$ \\
\hline Gallimimus & 6.80 & $\begin{array}{l}\text { Osmólska et al. } \\
\text { (1972) }\end{array}$ & Saurornitholestes & 2.25 & Benson et al. (2011) \\
\hline Garudimimus & $3.71^{*}$ & $\begin{array}{l}\text { Kobayashi \& } \\
\text { Barsbold (2005) }\end{array}$ & Shenzhousaurus & $\begin{array}{l}8.40 \\
1.91\end{array}$ & $\begin{array}{l}\text { Carrano (2005) } \\
\text { Benson et al. (2011) }\end{array}$ \\
\hline Gorgosaurus & 10.40 & Erickson et al. (2004) & Shuvuuia & $?$ & - \\
\hline Guanlong & 4.12 & Benson et al. (2011) & Sinornithoides & 1.40 & $\begin{array}{l}\text { Russel \& Dong } \\
\text { (1993b) }\end{array}$ \\
\hline Hagryphus & $?$ & - & Sinornithosaurus & 1.48 & Xu et al. (1999) \\
\hline Harpymimus & 4.50 & Benson et al. (2011) & Sinosauropteryx & 0.86 & Chen et al. (1998) \\
\hline Heyuannia & 2.27 & $\begin{array}{l}\text { measured from Lü } \\
(2002)\end{array}$ & Sinovenator & 1.18 & $\mathrm{Xu}$ et al. (2002) \\
\hline \multirow{2}{*}{ Huaxiagnathus } & \multirow{2}{*}{1.83} & measured from & Sinraptor & 8.76 & Currie \& Zhao (1993) \\
\hline & & Hwang et al. (2004) & Struthiomimus & 5.13 & \multirow{2}{*}{$\begin{array}{l}\text { Russell (1972) } \\
\text { Carpenter et al. } \\
\text { (2005a) }\end{array}$} \\
\hline IGM_100_42 & $?$ & - & Tanycolagreus & 3.56 & \\
\hline IGM_100_44 & $?$ & - & Therizinosaurus & $?$ & - \\
\hline Incisivosaurus & $?$ & - & Tianyuraptor & 2.05 & measured from \\
\hline Ingenia & 2.28 & Holtz (1994) & Troodon & 3.17 & Carrano (2005) \\
\hline Jeholornis & 0.75 & \multirow{2}{*}{$\begin{array}{l}\text { Zhou \& Zhang (2002) } \\
\text { Chiappe \& Göhlich } \\
\text { (2010) }\end{array}$} & Tsaagan & $?$ & - \\
\hline Juravenator & $0.52^{*}$ & & Tugulusaurus & 2.15 & Rauhut \& Xu (2005) \\
\hline Khaan & 1.42 & Benson et al. (2011) & Tyrannosaurus & 13.43 & Brochu (2002) \\
\hline Mahakala & 0.79 & Turner et al. (2011) & Unenlagia & 3.80 & Novas et al. (2009) \\
\hline Mapusaurus & 13.00 & Coria \& Currie (2006) & Utah_taxon & $?$ & - \\
\hline$M e i$ & 0.81 & Xu \& Norell (2004) & Utahraptor & $?$ & - \\
\hline Microraptor & $\begin{array}{c}0.75- \\
0.97\end{array}$ & $\begin{array}{l}\text { Xu et al., (2003); } \\
\text { Turner et al. (2007) }\end{array}$ & Velociraptor & 2.38 & $\begin{array}{l}\text { Norell \& Makovicky } \\
\text { (1999) }\end{array}$ \\
\hline Microvenator & $1.24^{*}$ & Makovicky \& Sues & Wellnhoferia & 0.67 & Elzanowski (2001) \\
\hline Mirischia & $?$ & $\begin{array}{l}(1998) \\
-\end{array}$ & Yanornis & 0.56 & $\begin{array}{l}\text { measured from Zhou } \\
\text { \& Zhang (2001) }\end{array}$ \\
\hline Mononykus & 1.39 & Perle et al. (1994) & Zuolong & 3.36 & \\
\hline
\end{tabular}


